PONTIFÍCIA UNIVERSIDADE CATÓLICA DO RIO DE JANEIRO

\title{
Economia Circular e Gestão da Sustentabilidade: um estudo sobre a Coca- Cola Company Brasil
}

\author{
Rodrigo Villela Parcias
}

Trabalho de Conclusão de CuRso

Centro de ciências sociais - CCS

DEPARTAMENTO DE ADMINISTRAÇÃO

Graduação em Administração de Empresas 

หัด

Rodrigo Villela Parcias

Economia Circular e Gestão da Sustentabilidade: um estudo sobre a Coca-Cola Company Brasil

Trabalho de Conclusão de Curso

Trabalho de Conclusão de Curso, apresentado ao programa de graduação em Administração da PUC-Rio como requisito parcial para a obtenção do título de graduação em Administração.

Orientador (a): Ciro Torres

Rio de Janeiro

Dezembro de 2020 


\section{Agradecimentos}

Agradeço primeiramente a toda minha família, em especial aos meus pais, Carlos e Monica, por terem me dado a oportunidade de estudar na PUCRio e por todo amor e carinho ao longo da minha vida. Agradeço à minha irmã, Helena, por todo amor e cumplicidade que é hoje base de uma grande amizade.

Agradeço a todos os meus amigos, que foram fundamentais para me dar força nessa trajetória da faculdade. Sem vocês tudo teria sido muito mais difícil.

Agradeço à Empresa Júnior PUC-Rio, que por muito tempo foi a minha grande motivação para estar na faculdade, e que tanto me ensinou. Uma simples sala no Prédio Leme que não somente abriu oportunidades profissionais e acadêmicas para mim, mas também me deu as melhores experiências e amizades que eu jamais esperaria ter.

Por fim, agradeço ao corpo de professores e funcionários do IAG, por todo suporte, tempo e dedicação no objetivo de formar pessoas e profissionais qualificados. 


\section{Resumo}

Parcias, Rodrigo Villela. Torres, Ciro. Economia Circular e Gestão da Sustentabilidade: um estudo sobre a Coca-Cola Company Brasil. Rio de Janeiro, 2020. 60 p. Trabalho de Conclusão de Curso - Departamento de Administração. Pontifícia Universidade Católica do Rio de Janeiro.

Este artigo tem como objetivo apresentar os conceitos de gestão da sustentabilidade e economia circular através de um estudo sobre a Coca-Cola Company Brasil. A partir dessa apresentação, busca-se entender e analisar as ações da empresa, de forma a visualizar o seu posicionamento em relação à gestão da sustentabilidade e resíduos sólidos. O artigo começa com um referencial teórico explicando conceitos sobre sustentabilidade corporativa e economia circular, que serão então identificados nas práticas da empresa através de uma análise crítica de dados de fontes secundárias. Por fim, busca-se um olhar sobre como os conceitos poderiam se traduzir de forma mais efetiva nas ações da companhia, identificando pontos de inconsistência entre a teoria apresentada e a prática.

\section{Palavras-chave}

Economia Circular, gestão da sustentabilidade, Coca-Cola, indústria de bebidas, responsabilidade social, desenvolvimento sustentável, sustentabilidade corporativa. 


\section{Abstract}

Parcias, Rodrigo Villela. Torres, Ciro. Circular Economy and Sustainability Management: a study on Coca-Cola Company Brazil. Rio de Janeiro, 2020. 60 p. Graduation Work - Administration Department. Pontifical Catholic University of Rio de Janeiro.

This article aims to present concepts about sustainability management and circular economy through a study on the Coca-Cola Company Brazil. From this presentation the goal is to understand and analyze the company's actions, in order to visualize its position towards sustainability and solid waste management. The article begins with a theoretical framework with concepts about corporate sustainability and circular economy, which will then be identified in the company's practices through a critical analysis of secondary sources data. Finally, the article focus on looking at how the concepts could be translated more effectively into the company's actions, identifying points of inconsistency between theory and practice.

Key-words

Circular Economy, sustainability management, Coca-Cola, beverage industry, social responsibility, sustainable development, corporate sustainability, environmental, social and corporate governance. 


\section{Sumário}

1. Introdução 1

1.1. Objetivo Final 3

1.2. Delimitação 3

1.3. Relevância do Estudo 4

2. Referencial Teórico 5

2.1. Sustentabilidade 5

2.1.1. Desenvolvimento Sustentável $\quad 7$

2.1.2. Gestão Ambiental 8

2.1.3. Produção Mais Limpa $(P+L) \quad 10$

2.2. Economia Circular 12

2.2.1. Design Regenerativo 16

2.2.2. Cradle to Cradle 19

2.2.3. Biomimética 20

2.2.4. Logística Reversa 22

3 . Metodologia 24

4 . Análise dos dados coletados 26

4.1. A Coca-Cola Company Brasil e a Indústria de Bebidas 26

4.2. Relatórios de Sustentabilidade 30

4.2.1. A Gestão da Sustentabilidade na Coca-Cola Company Brasil 31

4.2.2. Um mundo sem resíduos 34

4.2.3. Garrafas Retornáveis $\quad 35$

5. Apresentação e análise dos resultados $\quad 40$

5.1. Descrição dos resultados $\quad 40$

5.2. Análise dos resultados $\quad 40$ 
6. Conclusões

44

Referências Bibliográficas

47 


\section{Lista de Figuras}

Figura 1: Alinhamento dos pilares da sustentabilidade corporativa

Figura 2: O tripé da sustentabilidade

Figura 3: As normas da série ISO 14000

Figura 4: Produção Mais Limpa

Figura 5: Comparação entre economias lineares e circulares

Figura 6: Diagrama sistêmico - Economia Circular

Figura 7: Trajetória do design ambientalmente responsável

Figura 8: Campanha de marketing contra a Coca-Cola

Figura 9: Principais empresas poluidoras de plástico no mundo

Figura 10: Histórico de redução do peso de embalagens PET

Figura 11: As garrafas retornáveis

\section{Lista de Gráficos:}

Gráfico 1: Total de insumos utilizados nas embalagens

Gráfico 2: Proporção de tipos de insumos usados nas embalagens

Gráfico 3: Participação das retornáveis no portfólio da Coca-Cola 


\section{1 . Introdução}

Segundo Barbieri (2007), a preocupação com o meio ambiente não pode ser considerada recente, mas foi apenas nas últimas décadas do século XX que ela de fato passou a fazer parte de agendas de governos e da sociedade como um todo. A partir da revolução industrial, houve um crescimento exponencial do uso de recursos do meio ambiente como forma de crescimento econômico e produção em massa. Novas tecnologias e melhores condições de vida proporcionaram um rápido crescimento populacional, com destaque para o surgimento de uma massiva classe média, que alavancou a demanda por bens e serviços, sendo esta diretamente proporcional ao uso crescente de recursos naturais (LIEDER; RASHID, 2016).

A partir desse contexto, a necessidade de revisitar a forma como nos relacionamos com o meio ambiente fica cada vez mais evidente e urgente. Assim, empresas passaram aos poucos a adotar medidas que fossem para além de seus interesses econômicos e financeiros, buscando abranger dimensões sociais, éticas e ambientais. Com isso, aos olhos dos stakeholders, atitudes consideradas socialmente relevantes passaram a ser decisivas para o fracasso ou sucesso das empresas de qualquer setor (COSTA; CARVALHO, 2005).

O conceito de Responsabilidade Socioambiental Corporativa, portanto, surge como uma tendência e quase uma obrigação para empresas que queiram se manter vivas em um ambiente de constante transformação onde questões ambientais vêm sendo tratadas com cada vez mais importância. Ainda assim, este é um campo que carece de estudos (MORETTI; CAMPANÁRIO, 2009) e, principalmente, de aplicações práticas e ações de tamanha relevância que possam gerar resultados visíveis e benéficos para o planeta.

Uma das alternativas apresentadas como formas de solução para este cenário foi a Economia Circular. O conceito busca se inserir dentro de um contexto de recursos escassos, geração de resíduos neutra e benefícios econômicos sustentáveis (LIEDER; RASHID, 2016). 
A Economia Circular propõe uma nova ótica contrária ao modelo linear que adotamos atualmente na maioria dos modelos de produção e econômicos. A Ellen Macarthur Foundation, uma das maiores referências sobre o conceito no mundo, coloca como objetivo da Economia Circular:

\begin{abstract}
Redefinir a noção de crescimento, com foco em benefícios para toda a sociedade. Isto envolve dissociar a atividade econômica do consumo de recursos finitos, e eliminar resíduos do sistema por princípio. Apoiada por uma transição para fontes de energia renovável, o modelo circular constrói capital econômico, natural e social (ELLEN MACARTHUR FOUNDATION, 2020a).
\end{abstract}

No ano de 2020, com o contexto da pandemia que colocou ainda mais em cheque a forma como os modelos econômicos atuais contribuem para o desenvolvimento sustentável, não há mais espaço para um pensamento estático. De acordo com Stahel (2016), a Economia Circular é uma alternativa que se mostra muito viável de ser adotada, atuando a partir da reutilização de tudo aquilo que for possível, reciclagem do que não puder ser reutilizado, reparação do que está prejudicado de alguma forma e remanufaturação daquilo que não pode ser reparado.

Tamanho é compromisso e o impacto que a inciativa da Economia Circular propõe que "CEOs de algumas das maiores empresas do mundo, formuladores de políticas, filantropos, acadêmicos e outros indivíduos influentes" se juntaram para apoiar a iniciativa. A declaração assinada por diversos líderes busca ser o início de uma mudança de grande impacto para o planeta (ELLEN MACARTHUR FOUNDATION, 2020b).

A Coca-Cola Company foi uma dessas empresas e em 2018 assumiu o compromisso do World Without Waste (WWW), um movimento para reduzir o impacto ambiental causado pela maior empresa de bebidas do mundo. A visão da empresa com esse compromisso é a de coletar e reciclar uma garrafa ou lata para cada vendida até 2030 (THE COCA-COLA COMPANY, 2020a).

Para isso a empresa vem buscando realizar mudanças nos tipos de embalagens utilizadas em seus produtos, assim como todo o processo de distribuição e reciclagem dos mesmos. Essas mudanças e inovações na cadeia produtiva da empresa são objeto de estudo deste trabalho. 


\subsection{Objetivo Final}

Este trabalho tem como objetivo final descrever, entender e analisar os conceitos de gestão da sustentabilidade e economia circular, a partir do estudo de em uma grande empresa do mercado de bebidas não alcoólicas.

A partir de uma abordagem teórica empírica, este estudo busca um olhar específico sobre as ações da Coca-Cola Company Brasil e seu comportamento em relação à gestão da sustentabilidade e resíduos sólidos. Com isso, busca-se compreender as melhores práticas de sustentabilidade que podem contribuir para o mercado de bebidas não alcoólicas, considerando o tamanho da importância dessas práticas para um desenvolvimento sustentável. Como mencionado anteriormente, a Economia Circular é uma alternativa que vem se tornando uma realidade em diferentes contextos e com uma importância cada vez maior e necessária.

\subsection{Delimitação}

O estudo será delimitado às práticas realizadas pela Coca-Cola Company Brasil relacionadas à temática da Gestão da Sustentabilidade e Economia Circular, e a importância dessas práticas para o atingimento da meta estabelecida para 2030. Para isso, foram observados os dados presentes nos relatórios de sustentabilidade da empresa dos anos de 2017, 2018 e 2019, além de outras fontes de informação, com foco no entendimento das práticas da empresa para gestão de resíduos sólidos gerados pelas embalagens. Essa análise busca as práticas mais relevantes para demonstrar e analisar a importância do impacto positivo gerado por essas ações no meio ambiente.

O conceito de Economia Circular é extremamente abrangente e busca mudanças estruturais e de grande porte, mas também pode ser observado em ações como as realizadas pela Coca-Cola Company. Assim, é importante buscar meios em que os resultados da aplicação de conceitos relacionados à Economia Circular sejam observados de forma clara, contribuindo para a compreensão do 
mesmo e para o aumento da sua importância e aplicação como uma forma de solução para as questões ambientais enfrentadas atualmente.

\subsection{Relevância do Estudo}

O tema do presente estudo se faz importante em função da sua relevância dentro do debate entorno do impacto ambiental causado por empresas de bebida em termos de resíduos sólidos. No momento atual, as práticas de grandes empresas como a Coca-Cola Company podem definir a forma como nos relacionaremos com o meio ambiente num futuro próximo. A análise da gestão da sustentabilidade dessas empresas é relevante não somente nesse aspecto, mas também para servir como um exemplo a ser seguido e transmitido para consumidores e outras empresas do setor (ou um exemplo a não ser seguido, em muitos casos).

O setor de bebidas não alcoólicas tem um impacto muito grande no meio ambiente e este estudo busca ser uma forma de entender de forma mais clara e crítica as práticas dentro da Coca-Cola Company Brasil que de fato tem um efeito positivo para o desenvolvimento sustentável, visto a necessidade de mudanças e propostas por novos modelos econômicos e de produção.

No que tange os ganhos para além da esfera social ambiental que a aplicação uma gestão ambiental eficiente pode gerar, muitas empresas se limitam a realizar investimentos na área de sustentabilidade com a prerrogativa de que isso geraria mais custos, mas estudos apontam que esse investimento na verdade pode gerar lucro em um longo prazo (BRASIL, 2020). 


\section{2 . Referencial Teórico}

Neste tópico são apresentados e discutidos aspectos conceituais e estudos relacionados a Sustentabilidade e Economia Circular, que servirão de base para a análise realizada.

\subsection{Sustentabilidade}

Segundo Andrews (2015), o chamado "modelo linear" de produção teve início na Revolução Industrial. Nesse momento, houve um grande aumento da quantidade e da velocidade em que bens materiais e serviços passaram a ser produzidos, muito em função da forte mecanização e do desenvolvimento de novos meios de produção.

Estimativas mostram que o consumo mundial cresceu seis vezes em 50 anos, ao mesmo tempo em que a população cresceu apenas 2,2 vezes (NINNI, 2010). Ou seja: o que aumentou de fato foi o consumo realizado por cada indivíduo, mostrando que a mudança nos padrões de consumo é determinante para esse crescimento. Esse crescimento, como veremos mais a frente, não se deu de forma sustentável e teve consequências gigantescas para o meio ambiente.

Diante desse cenário, a preocupação com a degradação dos recursos naturais renováveis e não renováveis e os riscos envolvidos com desastres ambientais ganharam muita relevância. A década de 60 foi o período em que foi possível identificar um crescimento visível da consciência ambiental. Nesse período, a autora Raquel Carson lançou o livro "A Primavera Silenciosa", sendo este considerado um grande marco para assuntos relacionados à Sustentabilidade e Gestão Ambiental (NASCIMENTO, 2012).

Com a evolução dessa temática, dada a sua importância, a discussão sobre Sustentabilidade Corporativa ganha força. A Sustentabilidade Corporativa envolve as práticas realizadas por uma corporação para o equilíbrio das 
dimensões estratégicas que a envolve: econômica, ambiental e social (SIMPÓSIO DE ENGENHARIA DE PRODUÇÃO, 2010). A dimensão econômica se relaciona com os resultados financeiros e econômicos da empresa, e como isso impacta os seus stakeholders, com especial interesse de, por exemplo, acionistas e investidores. A dimensão ambiental, foco do presente estudo, envolve os impactos que a empresa tem em termos dos recursos naturais utilizados pela mesma, sejam eles vivos ou não vivos, renováveis ou não renováveis, escassos ou não escassos. Por fim, a dimensão social se refere aos impactos relacionados com a sociedade em que a organização está inserida, envolvendo aspectos como as práticas trabalhistas e direitos humanos.

A Sustentabilidade Corporativa, portanto, se daria através do equilíbrio entre essas três esferas. Esse equilíbrio, como ilustrado abaixo, vem sendo cada vez mais demandado com o passar do tempo.

Figura 1: Alinhamento dos pilares da sustentabilidade corporativa

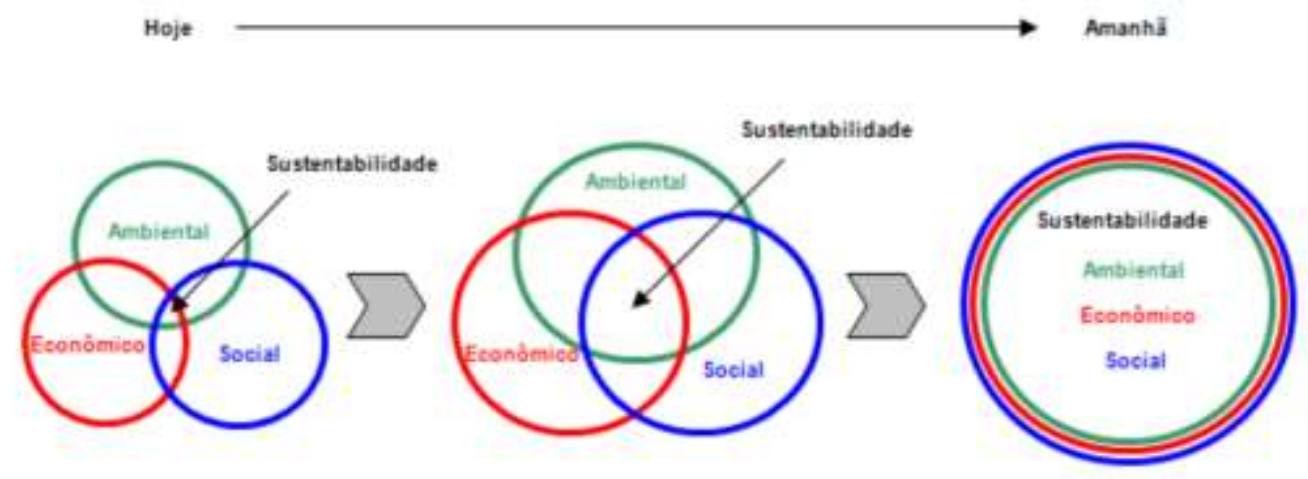

Fonte: Simpósio de Engenharia de Produção (2010)

Observa-se então uma mudança de paradigma dada a responsabilidade que as empresas passaram a ter para a manutenção dos recursos naturais do planeta. John Elkington (2001b, apud SESI, 2008, p.101-102) coloca que as empresas deveriam urgentemente superar a relação única com a esfera financeira, que ganhava a maior atenção, e passar a ter uma relação mais equilibrada. Constitui-se assim a lógica do triple bottom line, em que todos os stakeholders envolvidos têm a devida consideração em termos de valores e respeito, desde acionistas e funcionários até o meio ambiente e a sociedade como um todo. Haveria assim, portanto, uma mudança do single bottom line para o triple bottom line (SESI, 2008). 
Figura 2: O Tripé da Sustentabilidade

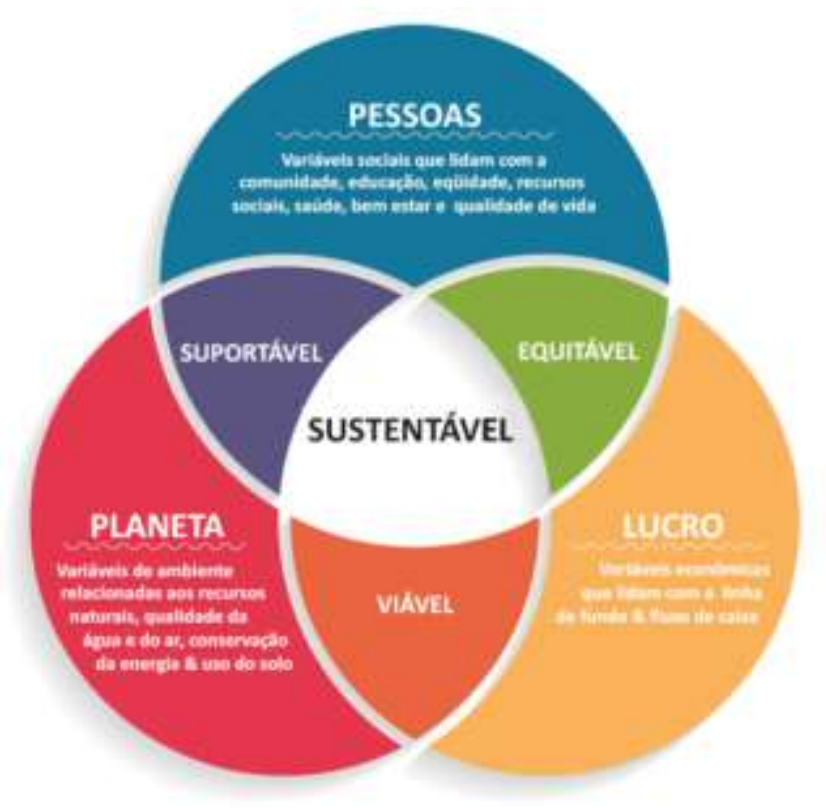

Fonte: Giovanelli (2015)

\subsubsection{Desenvolvimento Sustentável}

A partir da lógica apresentada anteriormente, o termo Desenvolvimento Sustentável passou a ser utilizado e comumente abordado para se referir a uma nova forma de produção e de desenvolvimento econômico. De acordo com Rabelo e Lima (2008), a necessidade de discussão e implementação desse termo se deu a partir dos estudos que mostraram a urgência de um possível colapso ambiental caso a relação entre o homem e meio ambiente continuasse a se dar de forma desorientada e desenfreada.

Este conceito apareceu pela primeira vez no Relatório de Brundtland na década de 1970, ganhando força a partir da Conferência Mundial de Desenvolvimento e Meio Ambiente, a Rio-92 (NASCIMENTO, 2012). A partir desse momento, ficou clara a necessidade de uma visão de desenvolvimento econômico que conseguisse ao mesmo tempo atender as demandas do ser humano e do meio ambiente. Com isso, toda lógica do Tripé da Sustentabilidade e suas três dimensões passaram a ser amplamente estudadas e utilizadas em diferentes meios, entre eles o meio corporativo, principalmente.

Dessa forma, com novos desafios e o equilíbrio entre as três esferas sendo buscado, o Desenvolvimento Sustentável exige: 


\begin{abstract}
Um sistema político que garanta a participação da população nos processos decisórios, um sistema econômico capaz de gerar excedentes, um sistema social que possa resolver tensões causadas por um desenvolvimento não equilibrado, um sistema de produção que preserve a base ecológica do desenvolvimento, um sistema tecnológico que busque constantemente novas soluções, um sistema internacional que estimule padrões sustentáveis de comércio e financiamento, e por fim, um sistema administrativo capaz de se autocorrigir (NASCIMENTO, 2012, p. 36).
\end{abstract}

Portanto, o desafio do Desenvolvimento Sustentável não é um assunto trivial, mas sim de grande complexidade e com exigências que vão para além dos principais interesses de stakeholders que compõem os mais diferentes mercados. A mudança de paradigma sugerida por essa mentalidade é urgente, mas em função de sua natureza não tão simples, enfrenta resistência dos mais diferentes tipos, mas de fato já trouxe mudanças significativas nos modelos de gestão das empresas.

\title{
2.1.2. Gestão Ambiental
}

Sistemas de Gestão Ambiental passaram a ser discutidos e elaborados, uma vez que a necessidade por modelos desse tipo começou a crescer muito. Assim, naturalmente, diferentes fabricantes passaram buscar algum tipo de padronização em produtos e processos que pudessem atuar em favor de redução de custos e aumentos na escala de produção, estando tudo de acordo e sem malefícios ao meio ambiente (NASCIMENTO, 2012).

Assim surgiu a International Organization for Standardization (ISO), que passou a ser a organização referência para a elaboração de normas visando a facilitação do comércio internacional e proporcionando uma credibilidade para os adotantes das medidas propostas. A série ISO 14000 é o tipo de certificação que definiu uma série de orientações sobre "auditorias ambientais, avaliação de desempenho ambiental, rotulagem ambiental e análise do ciclo de vida dos produtos" (NASCIMENTO, 2012, p. 103), o que possibilitou uma maior clareza sobre os aspectos ambientais mais relevantes para as empresas, além de padronizar e as diretrizes tratadas internacionalmente. 
Figura 3: As Normas da Série ISO 14000

\begin{tabular}{|c|c|}
\hline Norma & Temas \\
\hline ISO 14001 & $\begin{array}{l}\text { Sistemas de Gestảo Ambiental- Especificaçes e diretrizes para } \\
\text { uso }\end{array}$ \\
\hline ISO 14004 & $\begin{array}{l}\text { Sistema de Gestào Ambiental - Diretrizes gerais sobre principios e } \\
\text { técnicas de apoio }\end{array}$ \\
\hline ISO 14015 & Gestảo Ambiental - Avatiaçăo ambiental de locais e organizaçoes \\
\hline ISO 19011 & $\begin{array}{l}\text { Diretrizes para Auditorias de Sistemas de Gestào de Qualidade } \\
\text { e/ou Ambiental }\end{array}$ \\
\hline 15014020 & Rótulos e Declaraçōes Ambientais - Principios Gerais \\
\hline ISO 14021 & $\begin{array}{l}\text { Rótulos e Declaraçbes Ambientais - Autodeclaraçóes Ambientais } \\
\text { (Rotulagem Ambiental - Tipo II) }\end{array}$ \\
\hline ISO 14024 & $\begin{array}{l}\text { Rótulos e Declaracōes Ambientais - Rotulagem Ambiental Tipo I. } \\
\text { Principios e Procedimentos }\end{array}$ \\
\hline ISO 14031 & $\begin{array}{l}\text { Gestăo Ambiental - Avaliaçăo de Desempenho Ambiental - } \\
\text { Diretrizes }\end{array}$ \\
\hline ISO 14040 & $\begin{array}{c}\text { Gestão Ambiental - Avaliação do Ciclo de vida - Principios e } \\
\text { Estrutura }\end{array}$ \\
\hline ISO 14041 & $\begin{array}{l}\text { Gestăo Ambiental - Avaliaçâo do Ciclo de Vida - Avaliaçào de } \\
\text { objetivo, escopo e análise de inventário }\end{array}$ \\
\hline ISO 14042 & $\begin{array}{l}\text { Gestão Ambiental - Avaliaçâo do Ciclo de Vida - Avaliação do } \\
\text { impacto do ciclo de vida }\end{array}$ \\
\hline ISO 14043 & $\begin{array}{l}\text { Gestảo Ambiental - Avaliaçào do Ciclo de Vida - Interpretaçăo do } \\
\text { ciclo de vida }\end{array}$ \\
\hline ISO 14050 & Gestào Ambiental - Vocabulário \\
\hline
\end{tabular}

Fonte: Oliveira (2020)

A partir dessas normas, foram definidas diretrizes a serem seguidas pelas empresas, definindo assim diferentes condutas ambientais que proporcionem sempre avanços em relação ao tema de Gestão Ambiental. Dentre esses avanços podemos destacar o desenvolvimento de um Sistema de Gestão Ambiental (SGA).

No caso de empresas que queiram obter a certificação, é necessário passar por uma série de requisitos. Primeiramente, é necessária a definição de uma política ambiental e seu comprometimento com a mesma, identificando os aspectos ambientais das atividades do negócio e impactos ambientais associados. É exigido o desenvolvimento de um SGA a partir desses aspectos, com a transformação da política ambiental em objetivos e alvos específicos, implementando o SGA de forma clara. Com isso, é preciso ter toda a comprovação e geração de documentos desses processos, assim como um controle operacional e um monitoramento da eficácia do SGA. 
Por fim, uma vez que haja uma auditoria ambiental que comprove todos os aspectos citado, a organização pode ser enquadrada como dentro dos padrões estabelecidos pela legislação ambiental. Com isso, pode se dizer a organização tem um comprometimento com a preservação do meio ambiente de forma comprovada e eficiente (SESI, 2008).

\subsubsection{Produção Mais Limpa $(P+L)$}

Uma das mais importantes ferramentas da Gestão Ambiental é a Produção Mais Limpa $(P+L)$. Essa alternativa busca ser uma alternativa de prática a ser realizada dentro de modelos mais sustentáveis para as empresas.

A Produção Mais Limpa é a "aplicação contínua de uma estratégia ambiental preventiva e integrada, nos processos produtivos, nos produtos e nos serviços, para reduzir os riscos relevantes aos seres humanos e ao ambiente natural" (LACOMBE; HEILBORN, 2015). Ou seja, essa alternativa busca propor alternativas das mais variadas para que empresas possam reduzir os impactos gerados por resíduos diversos no meio ambiente.

Essa metodologia busca então uma aplicação em diferentes níveis, desde a mais simples avaliação crítica de melhorias nas atividades do negócio, até uma aplicação mais robusta de um programa de P+L (CETESB, 2005). Um dos objetivos centrais é integrar a mentalidade de se ter metas e targets ambientais, assim como existem objetivos financeiros e processos de produção específicos.

Dentro dessa metodologia tem-se como prioridade a minimização de resíduos e emissões no nível 1, ou seja, uma redução diretamente na fonte e que possibilite uma modificação no processo logo em seu início. Caso isso não seja possível, os resíduos deveriam ser reciclados internamente, sendo reintegrados ao processo produtivo da própria empresa, o nível 2. Como última alternativa, esses resíduos seriam reciclados externamente, já não estando mais dentro da cadeia produtiva da empresa, o que já não seria a medida mais ideal a ser tomada (CNTL, 2003). 
Figura 4: Produção Mais Limpa

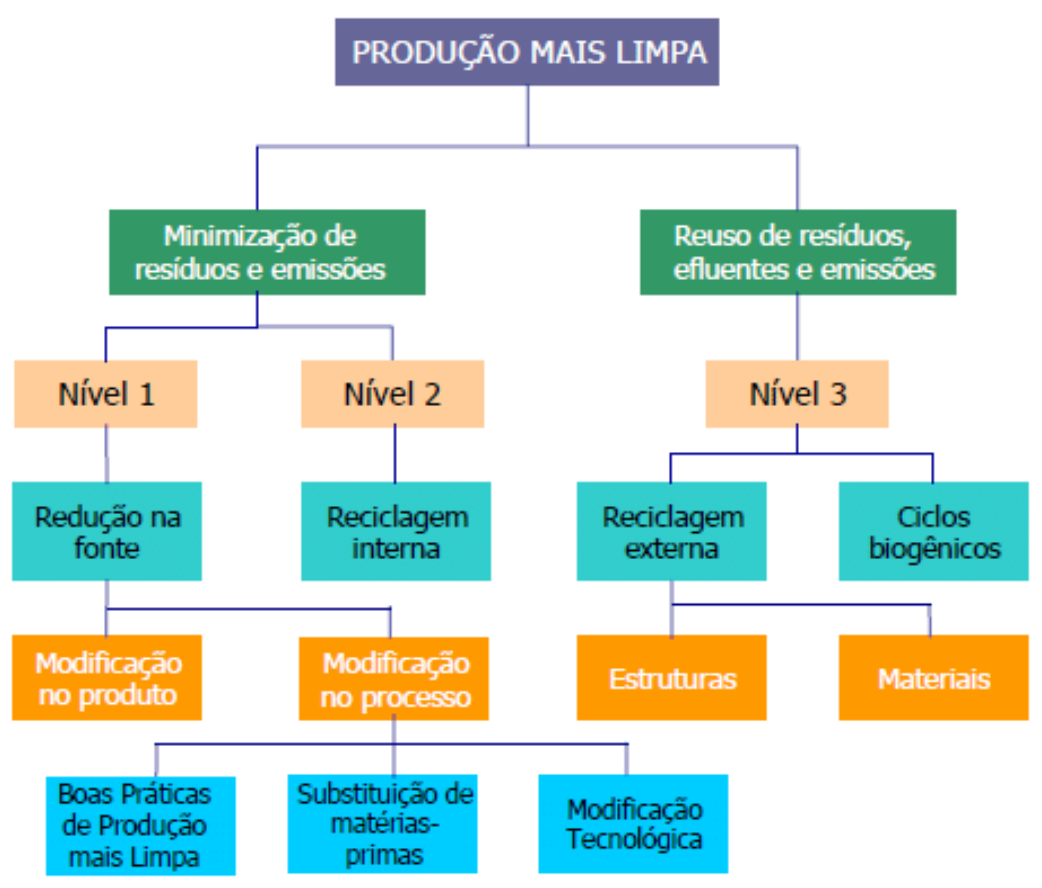

Fonte: Moraes (2020)

A implementação dessa metodologia seria subdividida nas seguintes etapas, de acordo com a Rede Brasileira de Produção Mais limpa: comprometimento da direção da empresa; sensibilização dos funcionários; formação do ECOTIME; apresentação da metodologia; pré-avaliação; elaboração dos fluxogramas; tabelas quantitativas; definição de indicadores; avaliação dos dados coletados; barreiras; seleção do foco de avaliação e priorização; balanços de massa e de energia; avaliação das causas de geração dos resíduos; geração das opções de $\mathrm{P}+\mathrm{L}$; avaliação técnica, ambiental e econômica; seleção da opção; implementação; e plano de monitoramento e continuidade. (CEBDS, 2006).

Como mencionado anteriormente na introdução, mudanças a favor do meio ambiente em processos dentro das organizações são investimentos: em um primeiro momento é necessário gastar mais e ter custo. Porém, posteriormente têm-se ganhos relevantes de eficiência nos processos, o que gera redução de custos a partir do menor consumo de insumos e de geração de resíduos e emissões nocivas (NASCIMENTO, 2012).

A Produção Mais Limpa, portanto, possibilita ganhos de forma direta no processo produtivo, assim como a diminuição de custos que estejam atrelados 
aos resíduos gerados. Assim, com a premissa de adotar um desenvolvimento sustentável e praticar a Gestão Ambiental de forma ativa, a Produção Mais Limpa se mostra como uma alternativa viável e um importante mecanismo de formação de Econegócios, isto é,

todo e qualquer empreendimento que se preocupa com as variáveis ambiental, social e econômica, e que seja proativo em criar mecanismos de proteção (preservação ou conservação) dos recursos, tanto naturais quanto culturais, desde a concepção dos produtos até a sua disposição final (LEMOS, 1998).

\subsection{Economia Circular}

Observamos hoje sistemas produtivos e modelos econômicos que atuam dentro de uma lógica linear, isto é, padrões que atribuem um início, um meio e um fim a tudo aquilo que de alguma forma é parte ativa do mesmo. Esse tipo de padrão não é sustentável em sua grande maioria: gera grande acúmulo de resíduos, pois não recebem nenhum tipo de reutilização, o que pode levar à escassez de recursos em função de uma exploração descontrolada, excessiva e desnecessária de matérias primas Andrews (2015).

A partir dessa lógica, fica evidente que o descarte de um produto ao final de sua vida útil não se caracteriza como uma prática sustentável, o que evidencia a necessidade de algum modelo que se coloque como substituto da economia linear. Algumas previsões confirmam ainda mais essa ideia: segundo Bonciu (2014), o mundo exigia um ano e meio para conseguir produzir e absorver todo o consumo de matéria-prima e geração de resíduos em 2010. De acordo com a ONU, se os padrões forem mantidos, até 2030 será necessário o dobro, e em 2050 o triplo.

Assim, a Economia Circular surge como uma grande alternativa para mudar o cenário observado atualmente, sendo "uma nova forma de olhar as relações entre o mercado, clientes, recursos naturais e a sociedade" (WBCSD, 2017). A ideia proposta por esse modelo é a de gerar um fluxo circular de recursos, através do reuso e da reciclagem, de forma alternativa a qualquer tipo de mentalidade linear, que necessariamente leva a um fim. A nova percepção propõe que os recursos são retirados do meio ambiente através de um processo 
circular, onde aquilo que seria desperdício pode se tornar um recurso inédito, sendo reinserido de forma indefinida no processo (ARAÚJO; QUEIROZ, 2017).

Uma comparação é feita por Stahel (2016), que exemplifica de forma clara a diferença entre a economia circular e a economia linear: o autor utiliza uma metáfora, comparando a economia circular com um lago, enquanto a economia linear seria um rio. Em um rio, os recursos naturais são levados e sendo transformados ao longo de todo seu curso, para no final conseguir desaguar em algum local e abastecer algum fim. Assim, um rio seria eficiente para superar a escassez e gerar grande volume, mas possuindo um término claro, que muitas vezes é escoado, gerando resíduos. Um lago, por sua vez, vive um constante reprocessamento de recursos e componentes, sem gerar nenhum tipo de externalidade para além do seu entorno.

Figura 5: Comparação entre economias lineares e circulares
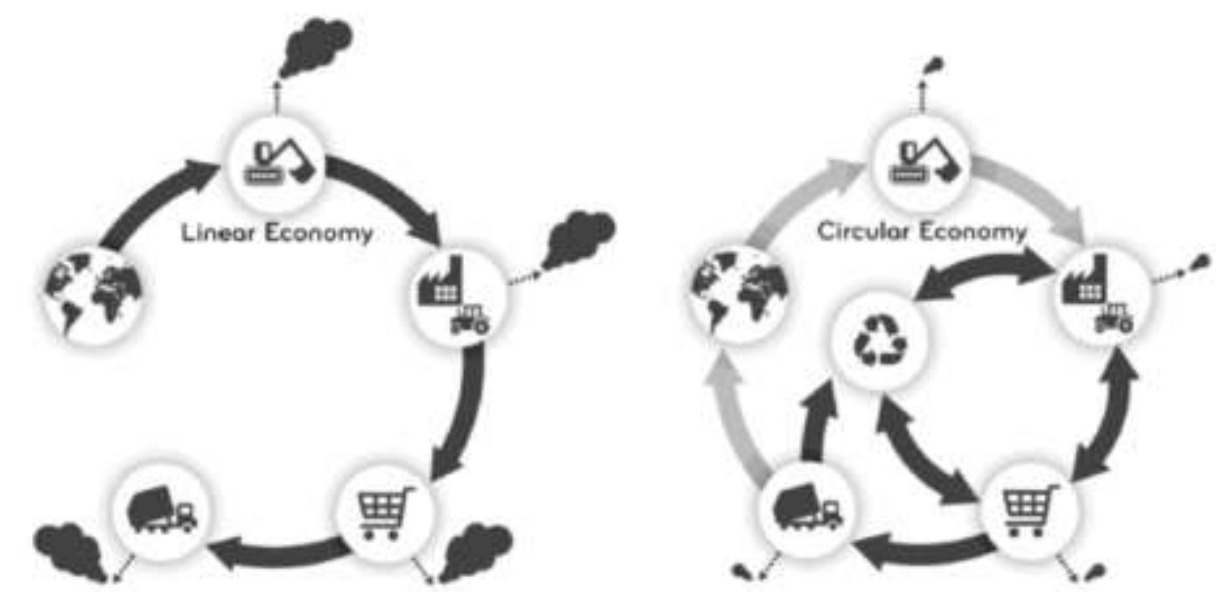

Fonte: Sauvé, Bernard e Sloan (2016)

A Ellen MacArthur Foundation (2020a) coloca três princípios básicos que sustentam a proposta da Economia Circular: preservação e aumento do capital natural, otimização da produção de recursos e fomentação da eficácia dos processos. O primeiro princípio propõe o uso de recursos naturais de forma a preservá-los ao máximo, uma vez que chegamos ao ponto em que estes correm o sério de risco de escassez. O segundo leva o lema de "nada se perde, tudo se transforma": fazer uso de uma mentalidade em que tudo que for utilizado deve ser feito de tal forma a gerar o mínimo de externalidade possível. O terceiro, por fim, propõe uma reavaliação dos processos como os meios de utilização dos recursos, e como estes também devem gerar bons resultados através de uma boa gestão de matérias primas (CEBDS, 2018). 
Figura 6: Diagrama Sistêmico - Economia Circular

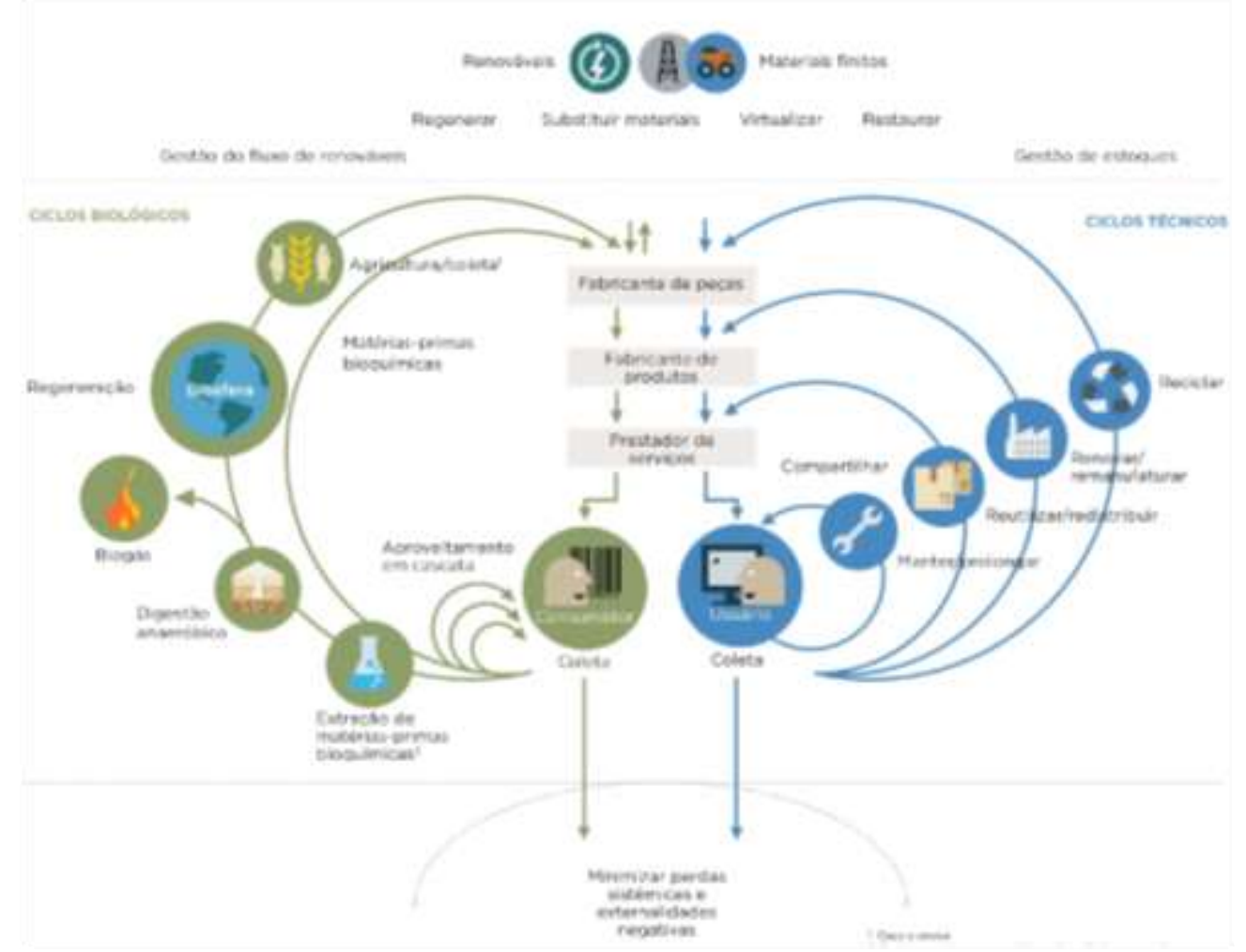

Fonte: Ellen Macarthur Foundation (2020a)

Como ilustrado na Figura 6, através da Economia Circular há a possibilidade de criação de sistemas cíclicos e com materiais que permitem um fluxo seguro e saudável para toda cadeia de produção e, principalmente, para a biodiversidade como um todo, incluindo os humanos. Os ciclos técnicos e biológicos, ideia que são parte do conceito de Design Regenerativo (LYLE, 1996) e do Design Cradle to Cradle (MCDONOUGH; BRAUNGART, 2002), são parte fundamental de todo esse processo e fundamentam todo o seu funcionamento.

Os materiais otimizados para o ciclo biológico são biodegradáveis ou obtidos a partir de matéria vegetal, e retornam seu valor como nutrientes biológicos para o solo. Os materiais otimizados para o ciclo técnico também são considerados nutrientes - nutrientes técnicos - e utilizados de modo que circulem em ciclos industriais fechados principalmente aqueles que não são produzidos de forma contínua pela biosfera (não-renováveis). (GEJER; TENNENBAUM, 2017).

O conceito da Economia Circular tem tamanha riqueza também em função da sua abrangência para além do campo teórico: seus princípios podem ser 
aplicados em diferentes esferas, desde um nível mais baixo, como em casas de famílias ou pequenas empresas, até um nível de economia mundial ou ecocidades (GENG et al., 2012). Nos níveis mais baixos os agentes podem aplicar o conceito através do uso de estratégias que possam contribuir para a circularidade dos recursos e para uma produção que gere menos externalidades dentro da cadeia produtiva.

Em um nível médio, como por exemplo, sistemas industriais, a ideia seria incorporar práticas que foquem no fluxo de materiais e energia que contribuam para a sustentabilidade em longo prazo: "políticas e estratégias para energia, materiais e consumo de água mais eficientes, enquanto emitem resíduos mínimos no meio ambiente" (ARAÚJO; QUEIROZ, 2017, p. 6).

Por fim, no maior dos níveis, a Economia Circular propõe a criação de parques e redes eco-industriais, gerando consequências positivas para economia e para o meio ambiente ao mesmo tempo, alinhadas com uma sociedade alinhada e direcionada para promoção de práticas voltadas para a sustentabilidade. (GENG et al., 2012).

A partir dessa ideia, a Ellen MacArthur Foundation propõe um conjunto concreto de ações que impulsionariam uma transição da economia linear para a economia circular. O estudo da "Nova Economia do Plástico" (ELLEN MACARTHUR FOUNDATION, 2020c) expõe uma série de princípios que norteiam as estratégias a partir do redesenho, reciclagem e reutilização.

O redesenho demonstra o quão fundamental é o pensamento de reprojetar e inovar por completo todo o conceito de embalagens plásticas. As embalagens atuais se mostram completamente fora da lógica circular uma vez que possuem uma séria de características que impedem uma otimização do seu destino final. As embalagens podem ser de pequenos formatos (destacáveis e tampas); embalagem multimaterial (com diferentes tipos de materiais); plástico incomum (plásticos de diferentes fontes de origem, o que dificulta a reciclagem); e podem ser altamente contaminadas em função do contato que tiveram com outros materiais (por exemplo, embalagens que foram usadas em fast food) (ELLEN MACARTHUR FOUNDATION, 2020c). 
A segunda estratégia, concentrada no pós-uso, mostra-se como uma alternativa necessária especialmente hoje em dia, em que boa parte das embalagens não pode ser reutilizada, mas sim reciclada. A reciclagem seria uma alternativa para reduzir os níveis de poluição no meio ambiente, assim como a emissão de gases causadores do efeito estufa (ELLEN MACARTHUR FOUNDATION, 2020c).

Por fim, a terceira estratégia busca a reutilização das mesmas embalagens dentro dos processos. Garrafas e sacolas plásticas são exemplos notórios que podem ser aplicados dentro dessa lógica e possuem muitas oportunidades para desenvolvimento (ELLEN MACARTHUR FOUNDATION, 2020c).

O mercado de embalagens dentro da lógica da Economia Circular é de um potencial gigantesco e estima-se que o reuso de embalagens pode ter uma oportunidade de retorno de até US\$ 10 bilhões (ELLEN MACARTHUR FOUNDATION, 2020c).

A partir desses princípios e ideias, a Economia Circular se estrutura com base em uma série de escolas de pensamento que contribuíram de alguma forma para a sua concepção. Como mencionado anteriormente, o conceito por si só não é ligado a um único autor, mas suas aplicações práticas são fundamentadas em uma série de conceitos (ELLEN MACARTHUR FOUNDATION, 2020c).

\subsubsection{Design Regenerativo}

Como exposto anteriormente, alternativas para um desenvolvimento sustentável são o principal desafio para que seja possível reverter o cenário ambiental negativo observado atualmente. Segundo Zari e Jenkin (2009), cada vez mais a definição de sustentabilidade vem tomando um rumo diferente: ainda é importante e fundamental buscar uma redução de impactos negativos em termos de emissão de carbono, água e resíduos, mas é preciso ir além.

Orr (1996) coloca que problemas de design são fundamentalmente o que causam as grandes questões ambientais que estamos vivendo atualmente. Ao analisarmos os tipos de produtos e tecnologias que foram sendo desenvolvidos 
ao longo dos anos, é evidente a sua incompatibilidade com um desenvolvimento sustentável. Dessa forma, indo além para soluções convencionais e de redução de impacto momentâneo, o autor coloca que um design ecológico e um desenvolvimento regenerativo servem como formas de compreensão de padrões naturais e que se conectam diretamente com a natureza. Com base nessa premissa, é preciso redesenhar por inteiro todos os componentes estruturais da nossa sociedade, ou seja, todas as nossas formas de design, desde produtos até serviços e políticas públicas.

O primeiro autor a falar sobre o Design Regenerativo foi John Tillman Lyle, definindo-o como um conceito baseado na agricultura que consiste na ideia de produtos e meios de produção que possam se auto sustentar por longa duração e sem a geração de qualquer tipo de resíduo, na forma como plantas e árvores vivem (LYLE, 1996). O autor coloca o conceito como base para alterar os meios de produção e criar um mecanismo autossustentável dentro de todo processo produtivo.

A Figura 6 a seguir resume bem a ideia do Design Regenerativo em contraste com sistemas degenerativos. Reed (2007) definiu a trajetória do design ambientalmente responsável. Em sua parte inferior, estariam situadas tecnologias criadas de forma convencional ou até mesmo minimamente orientadas para uma melhora relativa, como por exemplo, copos e canudos reutilizáveis. Porém, esses produtos e tecnologias trabalham de forma isolada e fragmentada, com enfoque apenas em melhoras tecnológicas pontuais. 
Figura 7: Trajetória do design ambientalmente responsável



Fonte: Reed (2007)

A parte de cima, por sua vez, já apresenta soluções que se encaixam dentro do conceito de sistemas regenerativos, sendo baseados no funcionamento de sistemas vivos e possuem três camadas: design restaurativo, reconciliatório e regenerativo. $\mathrm{O}$ design restaurativo propõe atividades que sejam capazes de restaurar sistemas locais e de forma ambientalmente correta e que permita um auto funcionamento. O design reconciliatório é aquele que inclui os seres humanos como parte do meio ambiente e dentro de todo o funcionamento maior. Por fim, o design regenerativo busca a ampliação do sistema como um todo, promovendo o escalonamento de todos os produtos em prol do meio ambiente de forma conjunta e integra (REED, 2007).

Fundamentalmente, o design como conhecemos hoje é uma forma construída dentro de um ideal com início, meio e fim. O que o conceito se propõe a fazer é mostrar os caminhos para a alteração dos que conhecemos hoje para uma ideologia circular e autossustentável. 


\title{
2.2.2. Cradle to Cradle
}

O conceito e processo Cradle to Cradle, do berço ao berço, foi inicialmente desenvolvido pelo arquiteto americano Bill Mc Donough e pelo químico alemão Michael Braugnart. O nome do conceito é uma referência direta ao modelo linear de produção característico da Revolução Industrial. Nessa época, muito dos processos produtivos utilizados eram referenciados como Cradle to Grave, do berço à cova, em função da sua metodologia em linhas de produção, que possuíam um início, meio e fim (MCDONOUGH; BRAUNGART, 2002).

Assim como boa parte dos conceitos que sustentam a Economia Circular, - Cradle to Cradle também leva em consideração características do meio ambiente para sustentar a sua concepção. McDonough e Braungart (2002) colocam que levando em consideração tamanha a importância da natureza, é impossível operar dentro de um sistema que não leve em consideração a sua saúde e conservação.

Dessa forma, os autores trabalham um modelo que propõe soluções universais de design. Isto é, modelos padronizados que prezem por menos variações e mais unidade entre todas as partes.

\begin{abstract}
Para atingir suas soluções de design universal, os fabricantes projetam para o pior cenário: projetam um produto para a pior situação possível, de maneira que ele funcione sempre com a mesma eficácia. Esse objetivo garante o maior mercado possível para um produto. Também revela a relação peculiar entre a indústria humana e o mundo natural, pois sempre projetar para o pior cenário reflete a suposição de que a natureza é inimiga. (MCDONOUGH; BRAUNGART, 2002, p. 208).
\end{abstract}

O Cradle to Cradle traz, portanto, a ótica do design como uma forma de resolver os problemas atuais vigentes atualmente, ao contrário de uma lógica mais ampla e em termos de indústria, por exemplo. Nesse sentindo, os autores trazem a ideia de ecoefetividade em oposição à ecoeficiência.

A ecoeficiência tem como principal característica minimizar e reduzir. Ou seja, traz a ideia de um equilíbrio entre aquilo que seria eficiência dentro da produção e as consequências existentes para o meio ambiente (VAVOLIZZA, 2016). Esse conceito, definido dessa forma, ressalta claramente uma intenção 
de preservar a atuação de empresas operando e competindo entre si, mas com a consciência de que devem agir de forma a não gerar impactos negativos no meio ambiente. Um dos grandes lemas da ecoeficiência é os três R's: Reduzir, Reusar e Reciclar.

McDonough e Braugnart (2002) vão então fazer grandes questionamentos e críticas à ecoeficiência no sentido que não é uma solução adequada e de longo prazo, e que prioriza o aumento e constante crescimento de indústrias e empresas, e não o meio ambiente.

\begin{abstract}
A abordagem ambiental do "mal menor" para a indústria tem sido crucial para transmitir mensagens importantes relativas à preocupação ambiental - mensagens que continuam a capturar a atenção pública e incitar uma importante pesquisa. Ao mesmo tempo, transmitem conclusões menos úteis: em vez de apresentar uma visão de mudança inspiradora e empolgante, as abordagens ambientais convencionais concentram-se sobre o que não fazer. Essas proscrições podem ser vistas como uma espécie de gestão de culpa de nossos pecados coletivos, um conhecido placebo da cultura ocidental. (MCDONOUGH; BRAUNGART, 2002).
\end{abstract}

A ecoefetividade, segundo os autores, traz uma proposta muito mais impactante, relevante e de longo prazo. A ideia seria a realização de ações que sejam efetivas e com resultado imediato e sustentável. Assim, a abordagem do Cradle to Cradle coloca tudo aquilo que é produzido para serem projetados da forma correta e mais benéfica para o meio ambiente, ao invés de manter uma lógica de tentar fazer reparos dentro de meios de produção e produtos que por si só já são maléficos para o meio ambiente em termos de sua concepção no design.

\title{
2.2.3. Biomimética
}

Um dos principais conceitos utilizados pela Economia Circular para fundamentar suas ideias é a Biomimética. Segundo Benyus (2002), autora do livro que abordou primeiramente esse conceito, a biomimética é uma forma de estudar as melhores ferramentas que a natureza possui, de forma aplicá-las no design de produtos e solucionar problemas mundanos. Por isso, seu livro propõe a "inovação inspirada pela natureza". 
Ainda segundo a autora, três princípios são colocados como fundamentais para a sustentação do conceito: natureza como modelo, que seria utilizar a natureza como uma referência para propostas de solução humanas. Natureza como medida, isto é, a natureza serve como uma forma de medir qual a relevância do que está sendo proposto, uma vez que há bilhões de anos a natureza vem se adaptando a novos cenários e mostrando o que é durável e sobrevive ao longo do tempo. Natureza como mentor, ou seja, a natureza não está para nós como um recurso, mas sim como um grande professor para gerar aprendizados.

Sua abordagem pode ser considerada extremamente radical se comparada com qualquer outra abordagem que posteriormente foi utilizada em nossa sociedade. Comparando, por exemplo, a revolução industrial com a revolução biomimética proposta pela autoria, os movimentos são fundamentalmente diferentes. O padrão apresentado pela autora coloca ideias em que a natureza está totalmente acima do ser humano, com diversos ensinamentos que podem ser eventualmente utilizados por nós.

Observa-se, portanto, que a interseção existente entre a Economia Circular e a Biomimética se dá em diversos pontos. Enquanto a Economia Circular propõe um novo modelo econômico e práticas para um consumo autossustentável, a biomimética se coloca como uma solução prática dentro de uma visão abrangente da relação entre o homem e a natureza.

Todos os princípios da Economia Circular, proposta pela Ellen MacArthur Foundation, estão relacionados com os princípios biomiméticos, chamados de Princípios da Vida. Demonstrando assim que a biomimética pode ser o meio para se ajudar na implementação da economia circular, que é um sistema restaurativo e regenerativo por natureza. A biomimética pode auxiliar a economia circular por meio da estruturação dos sistemas produtivos e da aplicação de práticas e ferramentas para desenvolver produtos e tecnologias que mimetizam a natureza. Tanto no tocante à circularização dos nutrientes técnicos quanto dos nutrientes biológicos, em ambos os casos sendo guiados pelos diferentes princípios da biomimética. (DUPIM, 2019, p. 67) 


\subsubsection{Logística Reversa}

A Logística Reversa pode ser definida de diferentes formas, dependendo da perspectiva em que é utilizada. O Reverse Logistics Executive Council (RLEC) a define da seguinte forma:

Processo do planejamento, implementação e controle da eficiência e custo do fluxo de matérias-primas, estoques em processo, produtos acabados e as informações correlacionadas do ponto do consumo ao ponto de origem com o propósito de recapturar valor ou para uma disposição apropriada. (RLEC, 2020)

A partir dessa definição entende-se que a Logística Reversa compreende tudo aquilo que faz o caminho reverso dentro de uma cadeia produtiva, desde o recall de um produto até ações para descarte correto de resíduos após o contato com o consumidor final. É principalmente nesse segundo ponto em que ocorre a interseção entre Logística Reversa e Economia Circular.

Em sua essência, a Logística Reversa propõe que todo o processo logístico das empresas seja prolongado para além do percurso direto de todos os componentes, sendo necessário considerar toda a cadeia em sentido reverso (BOWERSOX; CLOSS, 2004).

O ciclo de vida dos produtos está evidentemente mais curto em muitos casos, sendo esta uma forma de conseguir aumentar a compra e venda de mercadorias. Um exemplo claro vem da obsolescência programada de muitos smartphones e outras tecnologias que são relançadas a cada ano.

A obsolescência e a descartabilidade crescentes dos produtos observados nesta última década têm-se refletido em alterações estratégicas empresariais, dentro da própria organização e principalmente em todos os elos de sua rede operacional. Estas alterações se traduzem por aumento de "velocidade de resposta" em suas operações desde a concepção do projeto do produto até sua colocação no mercado, pela adoção de sistemas operacionais de alta "flexibilidade operacional" que permitam, além da velocidade do fluxo logística, a capacidade de adaptação constante às exigências do cliente e pela adoção de "responsabilidade ambiental " em relação aos seus produtos após serem vendidos e consumidos, o que costuma ser identificado como "EPR"( Extend Product Responsability) a chamada "Extensão de Responsabilidade ao Produto". (LEITE, 2002, p. 6) 
Dessa forma, evidencia-se a forma como a mentalidade de consumo está conduzindo organizações a terem ao mesmo tempo uma preocupação com o aumento da oferta de produtos e o destino final dos mesmos. A lógica ambiental da logística reversa se dá no ponto em que os resíduos gerados dentro de uma cadeia produtiva retornariam a sua origem. Esse fluxo tem uma relação direta com a reciclagem, uma vez que essa se propõe a reaproveitar os materiais coletados e gerar matéria-prima nova em seu ponto de origem.

A logística reversa traz um importante ponto que relaciona com a responsabilidade que cada empresa tem com os resíduos gerados ao final de sua cadeia. Isso porque trazendo uma mentalidade de que o caminho reverso também faz parte de todo o processo, tudo aquilo que não tem um destino final necessariamente precisa retornar para a sua origem, dessa forma contribuindo para o menor impacto ambiental das indústrias (LEITE, 2002). 


\section{Metodologia}

O presente estudo utiliza a metodologia de pesquisa descritiva explicativa, tendo como base fontes e dados secundários, coletados através de estudos e levantamentos em sites da internet, livros, publicações, jornais, artigos e, principalmente, os relatórios de sustentabilidade e comunicações da Coca-Cola Company Brasil em seu site oficial.

Segundo Vergara (1998, p.45),

a pesquisa descritiva expõe características de determinada população ou de determinado fenômeno. Pode também estabelecer correlações entre variáveis e definir sua natureza. Não tem compromisso de explicar os fenômenos que descreve, embora sirva de base para tal explicação.

Gil (1999), por sua vez, coloca que a pesquisa descritiva explicativa tem como objetivo identificar fatores determinantes para a ocorrência de um fenômeno, servindo como uma forma de aprofundar a realidade do objeto de estudo, explicando as relações de causa e efeito dos fenômenos.

Dessa forma, entende-se que o presente estudo possui ambas as características descritas anteriormente: é de natureza descritiva a partir de uma ampla revisão teórica e conceitual e das análises feitas sobre a indústria de bebidas e os temas de sustentabilidade corporativa que envolvem o setor, com foque na Coca-Cola Company Brasil. O referencial teórico busca abranger todos os fatos teóricos que sustentam as ações da empresa e que visam o desenvolvimento sustentável, gestão ambiental e a temática da Economia Circular, de forma a contextualizar todo o trabalho em seus principais pilares teóricos.

A partir disso, o estudo também toma uma natureza explicativa através do cruzamento das informações obtidas por fontes secundárias que demonstram as ações de sustentabilidade realizadas pela Coca-Cola Company Brasil com toda 
a descrição teórica citada anteriormente. Com isso, indo ao encontro à definição colocada por Gil (1999), busca-se trazer uma análise mais profunda sobre as ações da Coca-Cola Company Brasil, de forma a entender de mais detalhadamente a sua relevância, o que se dará com apoio de toda conceituação e fundamentação teórica apresentada. 


\section{$4 \quad$. Análise dos dados coletados}

Neste capítulo serão analisadas as principais ações da Coca-Cola Company Brasil na gestão ambiental da empresa, buscando compreender o posicionamento da empresa frente à temáticas como a Economia Circular e Sustentabilidade. Primeiramente, será abordado um contexto sobre a empresa e a indústria de bebidas, e seus impactos no meio ambiente. Esses dados foram coletados a partir de publicações no site da empresa, assim como notícias e reportagens sobre o tema.

Com base nesse contexto, então, serão analisados os dados relacionados à gestão ambiental da empresa e a Economia Circular. Um olhar especial será dado ao projeto das garrafas PET retornáveis, as chamadas "Retornáveis". Os dados foram coletados a partir dos relatórios de sustentabilidade da Coca-Cola Company dos anos de 2017, 2018 e 2019.

\subsection{A Coca-Cola Company Brasil e a Indústria de Bebidas}

A Coca-Cola Company tem um passado antigo e já muito conhecido, por se tratar de uma das maiores marcas da história e a sexta mais valiosa do mundo no ano de 2019 segundo a revista Forbes (BADENHAUSEN, 2020). O refrigerante surgiu derivado de um remédio contra dor de cabeça e distúrbios no sistema nervoso, no momento em que um farmacêutico chamado Dr. John Stith Pemberton decidiu produzir um xarope a partir de tal medicamento em 1886. O xarope foi misturado com água gaseificada e, dessa forma, nasceu o que refrigerante tão conhecido no mundo inteiro (THE COCA-COLA COMPANY, 2020b).

A marca cresceu muito desde então e teve sua primeira presença no Brasil no ano de 1941, em Recife, quando as primeiras unidades vindas dos Estados Unidos chegaram na cidade. Nesse momento também se iniciou a primeira produção do refrigerante em território nacional na fábrica de Água Mineral Santa Clara. A primeira fábrica da Coca-Cola foi inaugurada em São Cristóvão, no Rio 
de Janeiro, local que concentrava um grande polo industrial da cidade. Já em 1942, as primeiras unidades do refrigerante passaram a ser produzidas, com o concentrado e o gás vindo diretamente dos Estados Unidos (COCA-COLA BRASIL, 2020a).

O ano de 1945 marcou um dos mais fundamentais passos da Coca-Cola Company no Brasil, sendo fundamental para o entendimento de toda a cadeia de distribuição dos produtos da empresa em território nacional: o sistema de franquias. Esse modelo já era utilizado nos Estados Unidos e também em outros países onde a marca já estava presente. O refrigerante, então, passou a ser produzido por fabricantes autorizados e parceiros, que recebem os insumos e fazem toda a distribuição dos produtos (COCA-COLA BRASIL, 2020a). A empresa atua nesse modelo até hoje, possuindo um total de nove fabricantes espalhados por todas as regiões do país.

Com o passar dos anos, a empresa foi aumentando sua penetração no Brasil e, sempre orientada a partir das diretrizes da Coca-Cola Global, foi diversificando seu portfólio e seus tipos de embalagem. No histórico da empresa em seu site institucional, a primeira menção feita à reciclagem de embalagens se dá no ano de 1990.

\begin{abstract}
Em junho de 1990 foi lançada a lata de alumínio 100\% reciclável para toda a linha de produtos. Pouco depois, chegou ao mercado brasileiro a garrafa plástica Superfamília retornável de $1,5 \mathrm{~L}$. Além de prática, atendia às exigências da legislação internacional de proteção ambiental. O Brasil foi o terceiro país do mundo a adotar essa embalagem (depois de Alemanha e Holanda). Era a maior novidade em termos de embalagem em 50 anos. Em 1996, o Programa "Reciclou, Ganhou" marcou o pioneirismo da empresa em reciclagem no Brasil. (COCACOLA BRASIL, 2020a)
\end{abstract}

Essa tímida menção ilustra o começo de uma longa trajetória de críticas que a empresa viria a sofrer em função dos impactos ambientais causados por suas atividades a nível global. Diversas entidades apontaram a Coca-Cola Company como responsável por boa parte da poluição de plástico no mundo inteiro. Em 2019, a Coca-Cola foi considerada pelo segundo ano consecutivo a maior responsável pela quantidade de plástico encontrada nos oceanos (ÉPOCA NEGÓCIOS ONLINE, 2020). Segundo a pesquisa realizada por ONGs, universidade e associações, "foram encontradas 12 mil embalagens de produtos 
da Coca-Cola em 37 países, colocando a gigante do setor de bebidas no topo do ranking, com 43\% do total coletado" (ÉPOCA NEGÓCIOS ONLINE, 2020).

A reputação da empresa já chegou a tal ponto de sofrer duras críticas de entidades muito relevantes no meio ambiental, como o Green Peace. Em 2016 uma petição global contra Coca-Cola foi assinada, liderada pelo Green Peace do Reino Unido.

A organização acusa a Coca-Cola de
estar sufocando os oceanos com plástico. Como é a maior
fabricante de refrigerantes do mundo, a Coca-Cola precisa
tomar uma atitude. O Greenpeace não acusa somente a Coca-
Cola, mas também a Pepsi e a Nestlé. Juntas, as três
empresas seriam as que mais poluem os oceanos
(MESQUITA, 2020)

O caso resultou em campanhas de marketing contra a Coca-Cola, colocando-a em uma posição extremamente negativa em termos de responsabilidade ambiental. A imagem abaixo mostra uma campanha realizada pelo Greenpeace que inseriu adesivos nas máquinas de bebida com a palavra "Choke" (do inglês, "engasgar", uma alusão ao refrigerante "Coke"), fazendo referência ao impacto que o plástico tem em animais que se engasgam com restos de garrafas. 
Figura 8: Campanha de Marketing contra a Coca-Cola

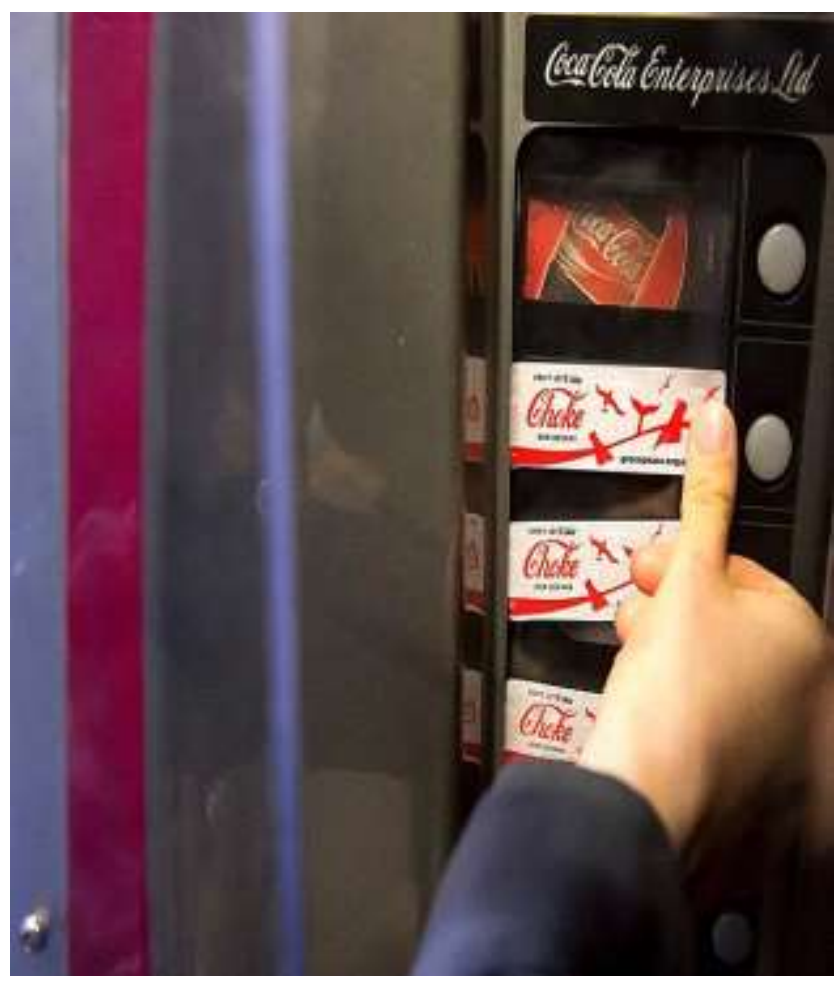

Fonte: Mesquita (2020)

Porém, como mencionado anteriormente, o impacto do plástico no meio ambiente não é uma exclusividade da Coca-Cola Company. A indústria de bebidas como um todo tem grande responsabilidade em função de toda sua lógica produtiva, que tende a gerar diferentes externalidades.

"No Brasil, a produção de refrigerantes destaca-se como o principal item do setor de bebidas, aparecendo em seguida à produção de cervejas. Os resíduos sólidos gerados na fabricação de refrigerantes decorrem principalmente dos processos de envase e de acondicionamento". (MEU RESÍDUO, 2020).

Entre os diferentes impactos que a indústria tem, os de maior destaque são os resíduos sólidos, que incluem latas de alumínio, garrafas PET e vasilhames defeituosos; resíduos de papel, papelão e plástico de embalagens; borras de rótulos de lavagem de garrafas; garrafas de vidro. Sem mencionar também efluentes líquidos e o consumo de água. (MEU RESÍDUO, 2020).

A organização Break Free From Plastic fez um levantamento em 2019 que mostrou as principais empresas responsáveis pela poluição de plástico no mundo. Nas três primeiras colocações estão empresas que fazem parte da 
indústria de bebidas, com destaque para a Coca-Cola, que das três é a única que joga somente no segmento do mercado de bebidas não alcoólicas (MEU RESÍDUO, 2020).

Figura 9: Principais empresas poluidoras de plástico no mundo em 2019

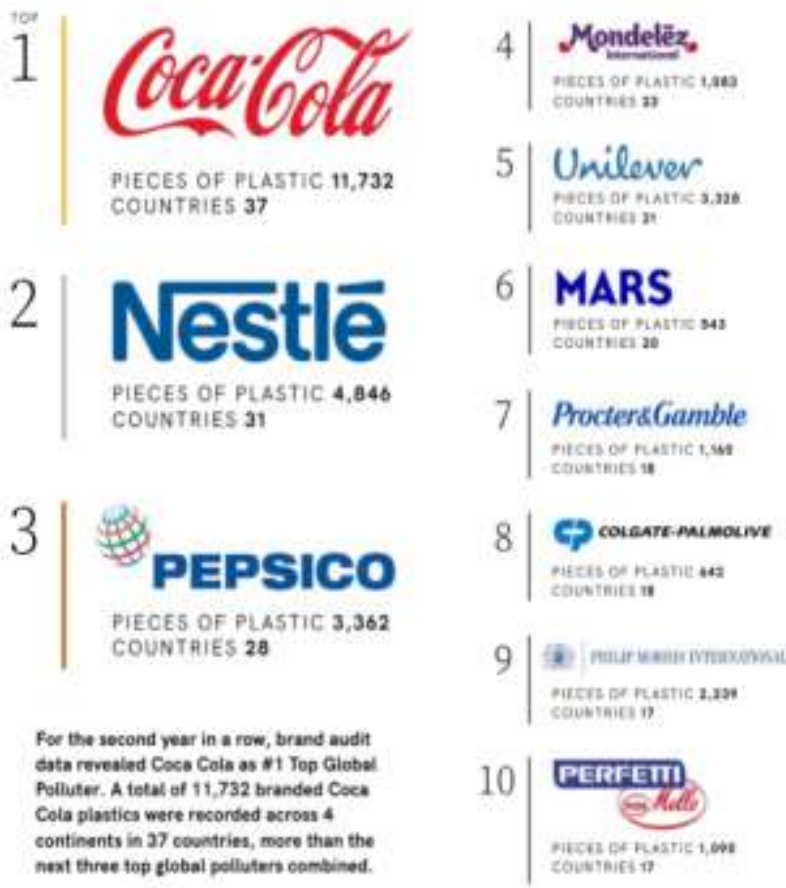

Fonte: Break Free From Plastic (2020)

Diante desse contexto, não haveria outra saída senão o desenvolvimento de projetos, ações e campanhas ambientais por parte dessas empresas, buscando justificar minimamente números tão assustadores. A seguir, analisaremos os relatórios de sustentabilidade da Coca-Cola Company, com foco no projeto das garrafas Retornáveis, uma solução encontrada pela empresa para diminuir o impacto de seus produtos no meio ambiente.

\subsection{Relatórios de Sustentabilidade}

Os relatórios de sustentabilidade da Coca-Cola Company Brasil tiveram a sua oitava edição divulgada no ano de 2020, referente ao ano de 2019. Os documentos seguem as normas da Global Reporting Initiative (GRI), opção Essencial, que conta com uma série de indicadores relacionados às atividades da organização. 
As Normas GRI representam as melhores práticas globais para o relato público de diferentes impactos econômicos, ambientais e sociais. $O$ relato de sustentabilidade com base nas Normas fornece informações sobre as contribuições positivas ou negativas de uma organização para o desenvolvimento sustentável (GLOBAL REPORTING INITIATIVE, 2020).

A seguir, faremos a análise de alguns dos números expostos nos relatórios dos anos de 2017, 2018 e 2019, com destaque para a iniciativa do "World Without Waste" (WWW), "Um mundo sem resíduos", lançada em 2018, e o projeto das garrafas Retornáveis. Vale ressaltar que nenhum dos relatórios da Coca-Cola foi submetido à verificação externa.

\subsubsection{A Gestão da Sustentabilidade na Coca-Cola Company Brasil}

"A Economia Circular como base da estratégia". Essa é a forma como a Coca-Cola Company Brasil define o seu posicionamento para atingir os objetivos e ambições relacionados ao meio ambiente e os impactos que seu negócio gera. (COCA-COLA BRASIL, 2020b). A empresa se guia a partir do estudo realizado pela Ellen MacArthur Foundation "A Nova Economia do Plástico", que coloca formas da indústria ser mais correta ambientalmente, destacando a redução do uso de recursos naturais, o aumento do uso de embalagens retornáveis e o investimento em logística reversa (ELLEN MACARTHUR FOUNDATION, 2020c).

Ainda tendo como base a publicação feita pela Ellen MacArthur Foundation, a empresa coloca três pilares da Economia Circular que sustentariam as práticas de produção para redução do impacto ambiental, já mencionados anteriormente: redesenho, reuso e reciclagem (COCA-COLA BRASIL, 2020b). O redesenho se refere às práticas de redução do peso das embalagens e da quantidade de insumos utilizados para sua produção. O reuso trata do reaproveitamento dessas embalagens criadas, buscando otimizar o seu ciclo de vida ao máximo. A reciclagem, por fim, se daria através do investimento em cooperativas de reciclagem, assim como uso de resinas recicláveis ao invés de resinas virgens (COCA-COLA BRASIL, 2020b).

Em relação ao primeiro ponto, a Figura 10 ilustra o esforço da empresa em reduzir o peso de embalagens PET, de forma a diminuir a quantidade de 
insumos utilizados na sua produção. Com isso, o impacto dos resíduos gerados é relativamente menor a partir distribuição dessas garrafas. Segundo a empresa,

\begin{abstract}
"a circularidade da embalagem começa quando ela é desenhada. A escolha dos materiais, a análise de sua reciclabilidade, o uso de cores e a quantidade de resina são aspectos que influenciarão na possibilidade de retorno ao ciclo industrial pós-consumo" (COCA-COLA BRASIL, 2020b, p. 61).
\end{abstract}

Figura 10: Histórico da redução do peso de embalagens PET da Coca-Cola

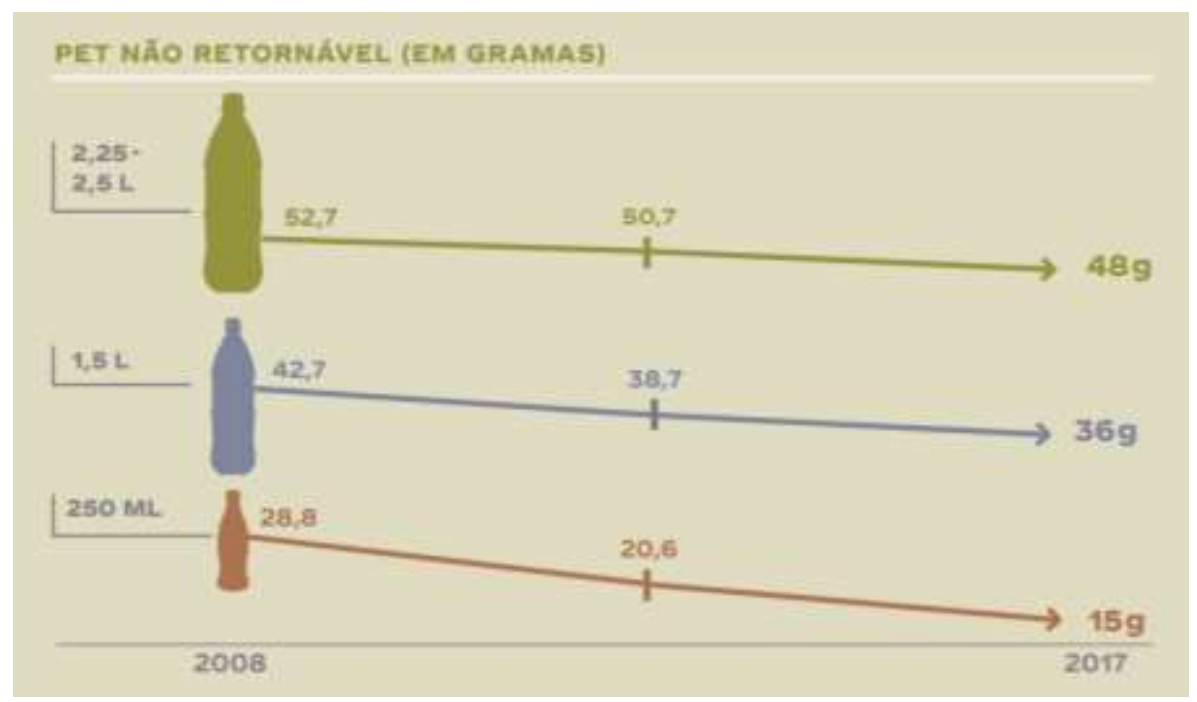

Fonte: Coca-Cola Brasil (2020b)

No que tange o segundo ponto, o reuso, a Coca-Cola se apoia muito na estratégia desenhada para as garrafas retornáveis. Essa garrafa pode ser reutilizada muitas vezes e cumpre o papel de aumentar o controle da empresa sobre os ciclos de uso de seus produtos. As garrafas retornáveis serão analisadas com mais detalhes mais à frente.

Por fim, em relação à reciclagem, a companhia vem realizando diversas ações já há alguns anos, de forma a contribuir para a diminuição do seu impacto residual no meio ambiente. Atualmente, a Coca-Cola Brasil investe em três grandes projetos de reciclagem: SustentaPET, Reciclar Pelo Brasil e Cataki (COCA-COLA BRASIL, 2020d). Segundo consta no relatório, a Associação Brasileira da Indústria do PET (Abipet) coloca que apenas um pouco mais da metade de toda quantidade de garrafas PET colocadas no mercado em 2019 foi reciclado no Brasil. 
Um ponto de atenção possível de ser observado nos dados disponibilizados nos relatórios de sustentabilidade de 2017, 2018 e 2019 é a proporção de utilização de insumos na produção total de embalagens da empresa. O gráfico 1 mostra uma variação de 17,7\% na quantidade de insumos utilizados para produção de embalagens em 2019, um aumento considerável em relação ao ano anterior, que veio de uma variação negativa em relação à 2017 .

Gráfico 1: Total de insumos utilizados nas embalagens, em mil toneladas

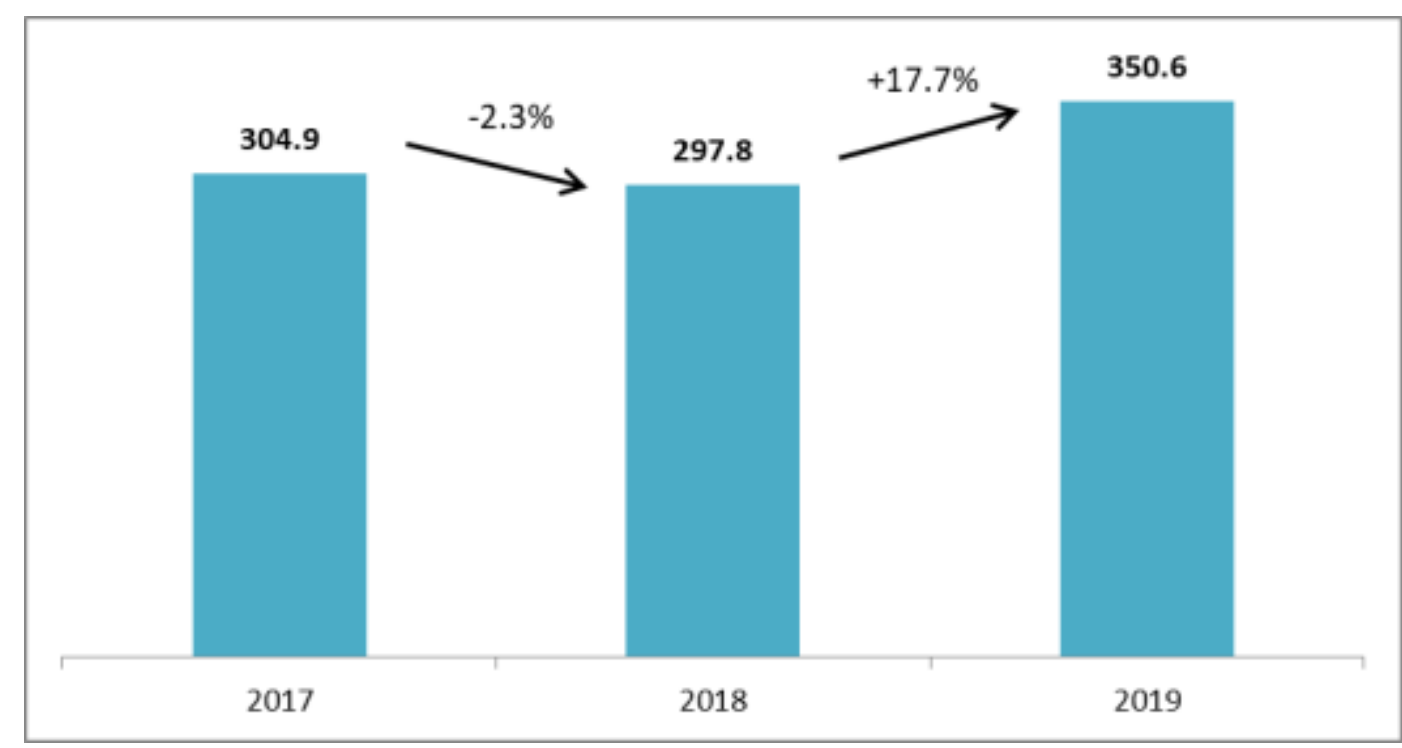

Fonte: Relatórios Coca-Cola Brasil de 2017, 2018 e 2019 - Elaboração Própria

Este número por si só indica apenas um aumento na produção anual da empresa, porém, juntamente com esse aumento houve um crescimento de insumos "novos" na proporção de insumos utilizados, como exposto no gráfico 2 , o que evidencia um descuido para utilização de matérias primas de fontes renováveis ou reciclados. 
Gráfico 2: Proporção de tipos de insumos utilizados nas embalagens

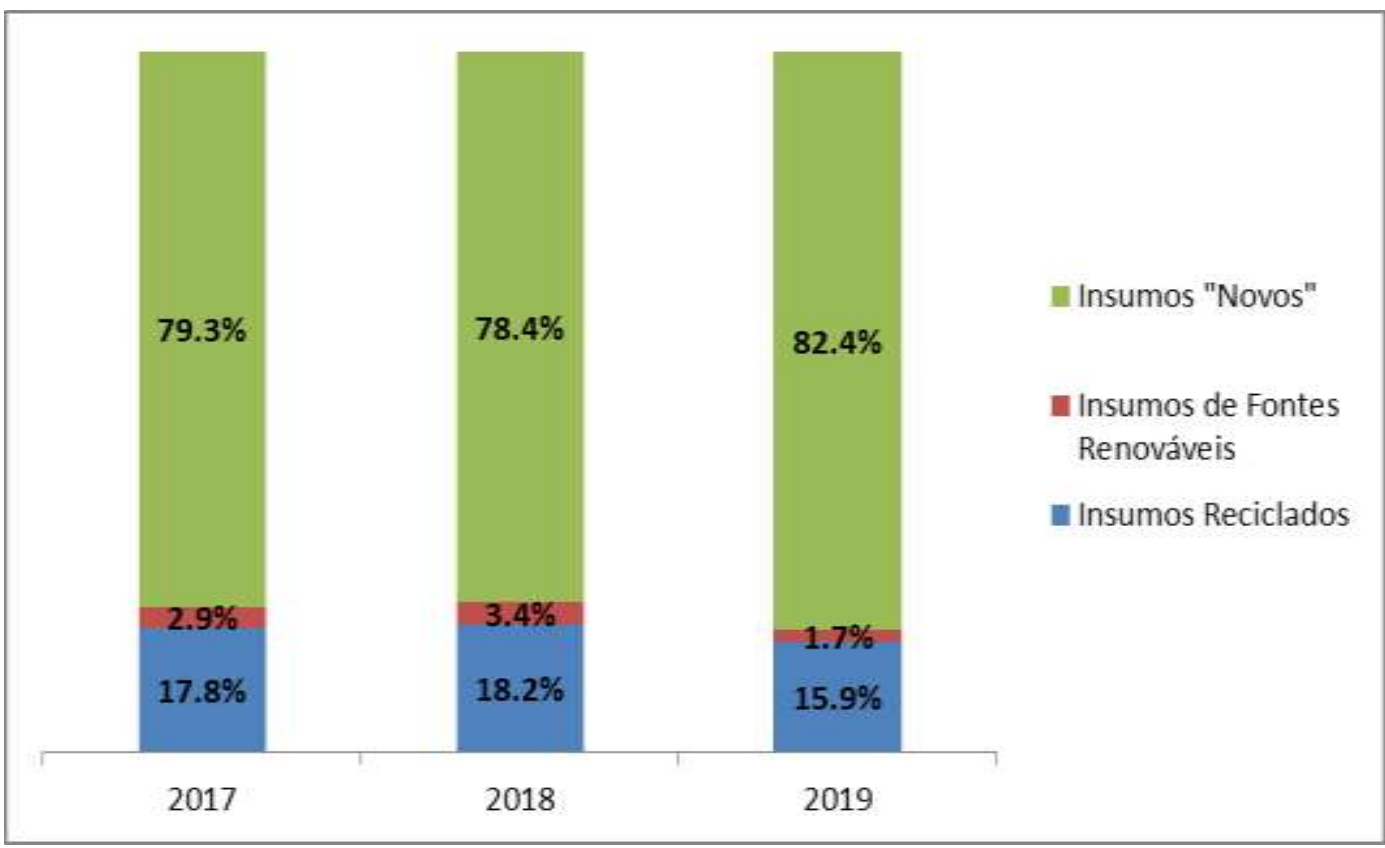

Fonte: Relatórios Coca-Cola Brasil de 2017, 2018 e 2019 - Elaboração Própria

\subsubsection{Um mundo sem resíduos}

Após ser colocada como a principal empresa poluidora de plástico no mundo inteiro em 2018, como citado anteriormente, a Coca-Cola Company Global tomou uma medida ambiciosa para tentar reverter essa situação: reciclar o equivalente a cada garrafa ou lata que vende globalmente até 2030 (THE COCA-COLA COMPANY, 2020c). Ou seja, a empresa pretende se tornar completamente neutra em termos de impacto de resíduo sólido até o ano de 2030.

Consumidores do mundo inteiro se preocupam com o planeta. Eles querem e esperam que companhias como a nossa sejam líderes e contribuam para que um mundo livre de resíduos seja possível. Através dessa visão 'Mundo sem resíduos', estamos investindo no planeta e em nossos recipientes para ajudar a transformar o problema das embalagens em algo do passado. (THE COCA-COLA COMPANY, 2020c).

Todas as unidades da Coca-Cola Company foram convocadas para esse movimento, incluindo a organização brasileira, naturalmente. Com isso, cada uma das Business Units passou a desenvolver projetos que contribuíssem diretamente com a meta de 2030. Com isso, objetivos foram traçados buscando repensar todas as embalagens do portfólio de bebidas da empresa dentro da 
perspectiva da Economia Circular, entre eles: aumentar a porcentagem de embalagens retornáveis no portfólio; diminuir a quantidade de matéria prima necessária para a produção de novas embalagens; aumentar o uso de insumos recicláveis em embalagens; investir no processo de logística reversa das embalagens descartáveis, através do desenvolvimento social e estrutural de cooperativas de catadores no Brasil (COCA-COLA BRASIL, 2020c).

Um dos projetos que se destacou na unidade brasileira foi a garrafa PET retornável, como veremos no tópico a seguir. Esse é a principal aposta da empresa para conseguir atingir a meta do mundo sem resíduos (COCA-COLA BRASIL, 2020b).

\subsubsection{Garrafas Retornáveis}

As garrafas retornáveis não são uma novidade ou uma inovação recente criada pela Coca-Cola Company. Por muito tempo a distribuição de refrigerantes e outras bebidas era feita através de garrafas de vidro que retornavam para fábricas e lojas após o consumo. Nos anos 90, as vendas da Coca-Cola Company no Brasil eram feitas dessa forma, com uma logística própria para recolhimento das garrafas de vidro, como mencionado anteriormente (COCACOLA BRASIL, 2020e).

Porém, a chegada de garrafas PET descartáveis ao mercado fez com que a participação das retornáveis de vidro nos portfólios de empresas de bebida caísse muito. Nesse momento, as garrafas descartáveis passaram a ter uma relevância maior, pois o custo para produção e distribuição de bebidas se tornou muito menor em comparação com as garrafas retornáveis de vidro, que então passaram a representar apenas $5 \%$ das vendas da Coca-Cola Company (COCACOLA BRASIL, 2020e).

As consequências dessa inversão de valores em termos de embalagens já são amplamente conhecidas, evidenciadas no tópico anterior, colocando a CocaCola Company como umas das maiores poluidoras de plástico do mundo. Diante disso, a empresa retomou o conceito de garrafas retornáveis na tentativa de diminuir o seu impacto no meio ambiente. A função de ser utilizada várias vezes é o pressuposto básico de uma garrafa retornável, e ainda na década de 90 a 
empresa desenvolveu uma PET retornável, que tinha uma função similar às garrafas de vidro (COCA-COLA BRASIL, 2020e).

Em 2018, porém, a empresa foi além e conseguiu criar um modelo de embalagem que aumentou ainda mais a eficácia de embalagens retornáveis. Foi criada a garrafa universal, que possui propriedades mais leves e formato único, permitindo que diferentes sabores de refrigerantes sejam colocados na mesma garrafa. Assim, se antes uma garrafa de Coca-Cola poderia ser retornada para ser reutilizada como Coca-Cola, hoje é possível que ela seja reutilizada com Fanta, Kuat e Sprite, que são outros refrigerantes da Coca-Cola Company (COCA-COLA BRASIL, 2020e). O lançamento das retornáveis universais exigiu o investimento de cerca de $\mathrm{R} \$ 1,6$ bilhão em cinco anos, pois contou com a instalação de uma nova infraestrutura que suportasse a operação: novas linhas de envase, rotuladores, vasilhames e também campanhas voltadas ao consumidor (COCA-COLA BRASIL, 2020e).

Figura 11: As Garrafas Retornáveis

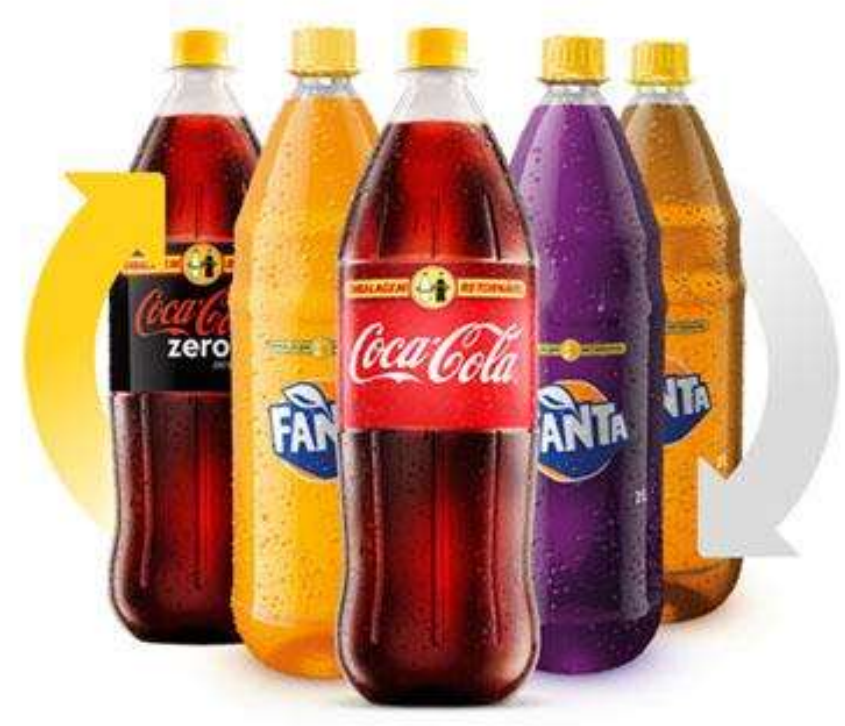

Fonte: Coca-Cola Brasil (2020g)

A garrafa retornável universal, como ficou conhecida, permitiu um crescimento no portfólio da Coca-Cola em padrões mais sustentáveis. Foi viável, assim, promover o reuso das garrafas de forma a diminuir as externalidades em resíduos plásticos. O projeto foi iniciado no Centro-Oeste, sendo expandido para São Paulo, Nordeste e Rio de Janeiro, posteriormente (COCA-COLA BRASIL, 2020e). 
Um estudo desenvolvido pela TriCiclos, uma consultoria ambiental, mostrou que a garra retornável universal possui o melhor índice de reciclabilidade dentro do portfólio da Coca-Cola Brasil. O objetivo desse índice é mostrar como os componentes presentes nas embalagens evidenciam a sua eficiência para gerar menos impacto no meio ambiente. As retornáveis possuem um índice de 89, dentro de uma escala que vai até 100 (COCA-COLA BRASIL, 2020b).

Dado o tamanho potencial das garrafas retornáveis desenvolvidas pela Coca-Cola Brasil, a empresa tomou a decisão de aumentar a participação dessa embalagem em seu portfólio. Dessa forma, a empresa vem buscando atingir esse objetivo desde 2010:

Gráfico 3: Participação das retornáveis no Portfólio da Coca-Cola Brasil



Fonte: Relatórios Coca-Cola Brasil de 2017, 2018 e 2019 - Elaboração Própria

Vale ressaltar que o número de $30 \%$ é a meta a ser atingida pela empresa no ano de 2020. Porém, dado o contexto da pandemia e a diminuição geral dos investimentos da empresa, esse resultado muito provavelmente não será atingido.

As garrafas retornáveis utilizam a resina PET em sua produção, mas possuindo aspectos diferentes em relação às garrafas PET tradicionais. As 
retornáveis são consideravelmente mais duras, possibilitando 25 ciclos de uso. Possuem uma redução de $14 \%$ no peso e tem rótulo de papel. Ou seja, uma mesma garrafa pode passar por até 25 consumidores diferentes até não ser mais utilizável. A consequência disso é uma diminuição gigantesca na produção de novas embalagens, chegando à redução de 200 milhões de garrafas em um ano no Brasil (COCA-COLA BRASIL, 2020b).

Além da redução na geração de resíduo plástico, há também outro ganho ambiental: diminuição na emissão de carbono. Apesar de o processo de logística reversa ser nocivo nesse aspecto, uma vez que há o transporte das garrafas retornáveis da fábrica para o supermercado repetidas vezes, esse dano é compensado em função do maior controle da utilização das garrafas e seu destino final. Todas as garrafas retornam para as fábricas quando não podem mais ser utilizadas, o que garante sua reciclagem correta ao final do processo. (COCA-COLA BRASIL, 2020b). O índice de carbono das retornáveis é $62 \%$ menor do que das garrafas tradicionais (COCA-COLA BRASIL, 2020e).

Outro ponto que gera debate sobre as retornáveis é sobre o uso de água para limpeza das garrafas, que também seria nocivo ao meio ambiente. Apesar disso, a Coca-Cola assume "o compromisso de manter o baixo índice de uso de água por litro de bebida produzido, por meio de melhorias na eficiência dos processos (COCA-COLA BRASIL, 2020e)".

\begin{abstract}
Um estudo de Avaliação do Ciclo de Vida (ACV) comprovou que a garrafa retornável de PET é uma embalagem mais sustentável que as garrafas retornáveis de vidro e de PET descartável, mesmo passando por ciclos de lavagem ao retornar à fábrica. A pegada hídrica dessas embalagens é menor do que a da similar descartável se consideradas as 16 voltas que as garrafas fazem às fábricas.(COCA-COLA BRASIL, 2020d).
\end{abstract}

Um aspecto fundamental para o sucesso das retornáveis no mercado tem relação direta com o consumidor. Além do fato de consumidores estarem ativamente mais atentos aos fatores sustentáveis de produtos e empresas, o preço das retornáveis é $30 \%$ mais barato do que as garrafas convencionais. Com isso, os consumidores se sentem atraídos ao produto não só por ele ser menos nocivo ao meio ambiente, mas também por pagarem menos por ele. (COCA-COLA BRASIL, 2020b). 
Uma pesquisa realizada pela Nielsen mostrou que em 2019 44\% dos lares pesquisados consumiram alguma embalagem retornável em 2019. Esse número foi o maior dos últimos anos e mostra um crescimento da popularidade do produto. (COCA-COLA BRASIL, 2020b). 


\section{5 . Apresentação e análise dos resultados}

Neste tópico será feita análise dos resultados do trabalho, através do cruzamento das informações expostas no referencial teórico e os dados e informações apresentadas a partir dos relatórios de sustentabilidade da CocaCola Company Brasil.

\subsection{Descrição dos resultados}

Os resultados do presente estudos buscam evidenciar aspectos positivos e negativos da gestão de resíduos da Coca-Cola Company, abordando os assuntos ligados à gestão da sustentabilidade na empresa e seu objetivo frente ao conceito da Economia Circular. Esses resultados foram obtidos através de uma análise crítica fundamentada em conceitos teóricos, buscando compreender as melhores práticas de sustentabilidade que podem contribuir para o mercado de bebidas não alcoólicas, considerando o tamanho da importância dessas práticas para um desenvolvimento sustentável.

\subsection{Análise dos resultados}

A partir dos dados coletados, fica evidente a preocupação da Coca-Cola Company Brasil em trazer o conceito da Economia Circular para o centro de sua gestão ambiental, de forma a se aproximar ao máximo da meta do Mundo sem Resíduos em 2030. A garrafa universal foi um lançamento pioneiro da Coca-Cola Company, sendo considerado um case internacional e reconhecido pela Fundação Ellen MacArthur Foundation (COCA-COLA BRASIL, 2020b). O case foi caracterizado como referência em Economia Circular e foi tomado como exemplo a ser seguido por outras empresas de bebida.

Assim, a Coca-Cola Company Brasil parece ambiciosa em relação a alcançar um desenvolvimento sustentável. A sustentabilidade corporativa da empresa atende o equilíbrio das esferas do triple bottom line, uma vez que, 
juntamente com a esfera financeira, há também ações voltadas para a esfera social e ambiental, como fica claro a partir das suas ações descritas anteriormente. A meta de 2030 coloca a esfera ambiental ainda mais em evidência, uma vez que esta é a principal vertente em que a empresa gera externalidades e impactos.

Os relatórios de sustentabilidade, porém, não evidenciam se a empresa cumpre os requisitos da ISO 14000, sendo este um dos referenciais mais respeitados para garantia de boas práticas de gestão ambiental. Apesar de haver menções a esse sistema de gestão ambiental em outras fontes (COCACOLA BRASIL, 2020f), não há nenhuma menção nos relatórios de sustentabilidade e estes não são submetidos à verificação externa, o que gera um ponto de questionamento em relação aos fatos expostos nos relatórios.

A Coca-Cola Company Brasil caminha dentro de objetivos muito ligados ao conceito de Produção Mais Limpa $(P+L)$, sendo um dos objetivos centrais do conceito a criação e cumprimento de metas e targets ambientais. A empresa possui números claros a serem atingidos e busca constantemente a melhora de indicadores relacionados às suas embalagens, como a porcentagem de participação das retornáveis no portfólio, o uso de insumos reciclados nas embalagens, além da grande meta de 2030. A empresa atua nos três níveis propostos pelo conceito, possuindo ações de minimização de resíduos e emissões, assim como o reuso de resíduos e efluentes.

Porém, do ponto de vista de gestão ambiental, a empresa tem uma deficiência na elaboração e divulgação de indicadores verificados e auditados, o que prejudica a sua atuação como um todo. Através dos indicadores da ISO 14000, por exemplo, seria possível ter um acompanhamento mais claro dos objetivos traçados, o que permitiria traçar ações mais certeiras e objetivas para gerar mais impacto ambiental positivo.

No que tange a Economia Circular, há diferentes aspectos a serem destacados na gestão ambiental da Coca-Cola Company Brasil. Como explicado, a ideia proposta por esse modelo é gerar um fluxo circular de recursos, através do reuso e da reciclagem, de forma alternativa a qualquer tipo de mentalidade linear, que necessariamente leva a um fim. Dessa forma, pode- 
se dizer que as retornáveis, assim como as práticas de reciclagem e a redução do peso das embalagens, se encaixam bem dentro desse conceito.

A empresa expõe claramente em seus relatórios o objetivo de estar alinhada com os três princípios básicos da economia circular: preservação e aumento do capital natural, otimização da produção de recursos e fomentação da eficácia dos processos. Porém, esse objetivo acaba se restringindo às ações específicas, e não engloba uma transformação mais radical do sistema como um todo.

Observando os conceitos que sustentam a Economia Circular, destacados no Referencial Teórico, as retornáveis estão dentro da ideia do Design Regenerativo. A trajetória de design ambientalmente responsável, proposta por Reed (2007), pode ser exemplificada a partir do caminho que as embalagens da Coca-Cola vêm percorrendo: a partir do surgimento das garrafas PETs, aprimoramentos foram sendo feitos nessas embalagens buscando características autossustentáveis, o que resultou na retornável universal, que só vai gerar algum tipo de resíduo após ser utilizada 25 vezes.

O conceito de Cradle to Cradle também pode ser observado na proposta das garrafas retornáveis universais. Uma vez que o conceito sugere um modelo de soluções universais de design, isto é, modelos padronizados que prezem por menos variações e mais unidade entre todas as partes, é evidente a relação direta com as retornáveis: uma embalagem única para todos os produtos.

O Cradle to Cradle, porém, propõe o rompimento com práticas que fazem apenas "reparos" para o meio ambiente, então um ponto de inconsistência por parte da Coca-Cola Company Brasil frente a este conceito seria o fato de que apenas parte do portfólio de bebidas é composto por garrafas retornáveis. Todo o seu portfólio em uma garrafa única seria muito mais efetivo e benéfico ao meio ambiente do que apenas $21 \%$, que foi a porcentagem do ano de 2019.

Analisando o conceito da Biomimética, a gestão ambiental da Coca-Cola Company Brasil ainda poderia ser mais adequada aos ideais propostos. Uma vez que o conceito propõe que a natureza está acima das relações produtivas e dos seres humanos, o uso de insumos de forma crescente e desproporcional em 
termos de insumos renováveis, reciclados e novos é um ponto de melhoria que a empresa poderia ter.

O conceito da Economia Circular, como mencionado anteriormente, é extremamente amplo, podendo ser aplicado em diferentes esferas. Assim, seria mais interessante se a Coca-Cola conseguisse expandir sua esfera de atuação para além dessas ações específicas. O World Without Waste consegue ter uma pegada muito alinha com o conceito, principalmente no sentido da circularidade dos recursos e resíduos: recolher uma garrafa para cada uma vendida pela empresa. Porém, uma mudança mais estrutural implicaria, por exemplo, em envolver todos os fabricantes e parceiros do sistema Coca-Cola, além dos próprios consumidores, de forma a gerar um ciclo completo dentro de suas operações.

Por fim, uma vez que lógica ambiental da logística reversa se dá no ponto em que os resíduos gerados dentro de uma cadeira produtiva retornariam a sua origem, é evidente que todos os projetos de reciclagem e coleta das embalagens da Coca-Cola expostos estão totalmente ligados à logística reversa. Além disso, o retorno das embalagens constantemente para as fabricas, pelo menos 25 vezes, é um exemplo muito bom de logística reversa, além do seu retorno final, quando esta é reciclada na própria fábrica.

A partir da análise desses resultados, evidenciando os pontos de interseção entre a gestão ambiental da Coca-Cola Company Brasil e todos os conceitos teóricos apresentados, é possível concluir que a empresa vem caminhando fortemente na busca por se tornar uma empresa ambientalmente responsável e possivelmente neutra em termos de resíduos até 2030. Porém, há ainda algumas inconsistências que poderiam ser aprimoradas para que esses resultados fossem obtidos de forma mais rápida e eficiente. 


\section{6 . Conclusões}

Ao longo do presente estudo foram analisados diferentes aspectos relacionados à indústria de bebidas não alcoólicas e, mais especificamente, a atuação da Coca-Cola Company Brasil como um dos principais agentes dentro desse mercado. Juntamente com todo referencial teórico apresentado, foi possível fazer uma análise ampla sobre a Gestão Ambiental da empresa, com um olhar especial para o conceito da Economia Circular, muito vigente atualmente e muito utilizado pela própria empresa em seus relatórios de sustentabilidade.

É importante ressaltar o tamanho do impacto que a indústria de bebidas como um todo tem no meio ambiente. Como exposto anteriormente, a poluição de oceanos com resíduos plásticos vindos de diferentes empresas de bebida, e também de outros ramos, é um problema gigantesco e que precisa de soluções urgentes. Projeções já deixam clara a necessidade de mudanças e as terríveis consequências que podemos enfrentar caso elas não se concretizem.

A Coca-Cola Company, sendo a maior empresa do setor de bebidas atualmente, tem naturalmente um papel muito grande nessas mudanças. Com uma atuação a nível mundial já há muito tempo, a empresa tem que assumir a responsabilidade pelos impactos que causou ao longo dos anos e deve o quanto antes agir na direção de mudanças bruscas, como já vem fazendo em certos níveis.

O recorte para a Coca-Cola Company Brasil nos permitiu uma reflexão sobre a atuação a nível nacional, em um país onde questões ambientais muitas vezes são negligenciadas por empresas privadas e órgãos públicos, o que amplifica um problema que já é naturalmente grande. A análise dos relatórios de sustentabilidade da empresa mostra com clareza a preocupação que a organização tem de mudar esse cenário. 
A Business Unit brasileira foi reconhecida internacionalmente pelo seu projeto das retornáveis e tem demonstrado boas iniciativas para contribuir com uma mudança de paradigma na questão de poluição de resíduos plásticos. Desenvolvido originalmente no Brasil, o projeto evidencia um potencial muito grande da Business Unit em desenvolver ainda mais soluções que agreguem alguns dos conceitos expostos no presente trabalho e que busquem minimizar as externalidades geradas pela empresa.

Os projetos de reciclagem e diminuição do peso das embalagens mostram a preocupação com o meio ambiente e com a reputação da empresa em termos de Gestão Ambiental. Ainda há pontos de melhoria e que poderiam ser implementados para tornar essas ações ainda mais eficientes, mas isso infelizmente ainda não ocorre.

A aplicação do conceito de Economia Circular e uso de fundamentos advindos desse conceito é muito presente nos relatórios da empresa, mas ainda assim é preciso ter um olhar crítico sobre o conteúdo exposto. Os relatórios de sustentabilidade são documentos que em sua vasta maioria expõem somente pontos positivos e ações afirmativas da empresa em questão, muitas vezes mascarando ou deixando de fora fatores que são extremamente importantes de serem mencionados.

Ainda assim, a meta do Mundo Sem Resíduos lançada em 2018 com o objetivo ambicioso de 2030 mostra que a empresa está globalmente comprometida com uma mudança radical de paradigma dentro da realidade do mercado de bebidas atual. Ainda há um longo caminho a ser percorrido, mas pelo menos os primeiros passos já estão sendo dados.

Como mencionado anteriormente, uma mudança estrutural no sistema Coca-Cola, com base no conceito da Economia Circular, seria de fato uma grande revolução por parte da empresa. Com base na avaliação dos ciclos técnicos e biológicos, a empresa poderia ser pioneira em investimentos para a geração de energia a partir da própria produção a partir do reuso de seus resíduos e matérias primas. Uma mudança na lógica de produção colocando em primeiro lugar o impacto socioambiental da empresa poderia ser revolucionária e servir de exemplo para outras empresas. 
Não há mais tempo para mantermos as mesmas práticas dos últimos anos. O ser humano é a espécie que mais causou impactos negativos no planeta, mas é também o que tem o maior potencial de causar impactos positivos. $E$ isso precisa ser feito agora. 


\section{Referências Bibliográficas}

ANDREWS, Deborah. The circular economy, design thinking and education for sustainability. Local Economy. Londres, p. 305-315. 2015.

ARAÚJO, Thaís Duek de; QUEIROZ, Adriane Angélica Farias Santos Lopes de. Economia Circular: Breve panorama da produção científica entre 2007 e 2017. In: ENCONTRO INTERNACIONAL SOBRE GESTÃO EMPRESARIAL E MEIO AMBIENTE, 19., 2017, São Paulo. Anais [...]. São Paulo: USP, 2017. p. 0-17

BADENHAUSEN, Kurt. As $\mathbf{1 0 0}$ marcas mais valiosas do mundo em 2019.

Disponível em: https://forbes.com.br/listas/2019/05/as-100-marcas-maisvaliosas-do-mundo-em-2019/. Acesso em: 02 nov. 2020

BARBIERI, José Carlos. Gestão ambiental empresarial: Conceitos, modelos e instrumentos. 2. ed. São Paulo: Editora Saraiva, 2007. 379 p.

BENYUS, Janine M. Biomimicry: innovation inspired by nature. Nova lorque: William Morrow \& Company, 2002. $320 p$

BONCIU, Florin. The European Economy: From a Linear to a Circular Economy. Romanian Journal of European Affairs. Amsterdã, v. 14, p. 78-91, 2014

BOWERSOX, Donald J.; CLOSS, David J. Logística Empresarial: o processo de integração da cadeia de suprimento. São Paulo: Atlas, 2004. 600 p.

BRASIL. ACADEMIA BRASILEIRA DE DIREITO. (org.). Investir na sustentabilidade pode gerar lucro. Disponível em:

https://abdir.jusbrasil.com.br/noticias/2331768/investir-na-sustentabilidade-podegerar-lucro. Acesso em: 05 out. 2020

BREAK FREE FROM PLASTIC (org.). The Brand Audit Report 2019.

Disponível em: 
https://www.breakfreefromplastic.org/globalbrandauditreport2019/. Acesso em: 08 nov. 2020

CEBDS - Conselho Empresarial Brasileiro Para o Desenvolvimento Sustentável. 5 perguntas pra você entender a Economia Circular. 2018. Disponível em:

https://cebds.org/publicacoes/5-perguntas-pra-voce-entender-economiacircular/\#.X73K72hKhGN. Acesso em: 17 out. 2020

CEBDS - Conselho Empresarial Brasileiro para o Desenvolvimento Sustentável. Guia da Produção Mais Limpa: Faça você mesmo. Rio de Janeiro: CEBDS, 2006. 60 p.

CETESB - Companhia de Tecnologia de Saneamento Ambiental. A produção mais limpa e o consumo sustentável na América Latina e Caribe. São Paulo: CETESB, 2005. 134 p.

CNTL - Centro Nacional de Tecnologias Limpas SENAI-RS. Cinco Fases da Implantação de Técnicas de Produção mais Limpa. Porto Alegre: CNTL SENAI-RS, 2003. $102 \mathrm{p}$.

COCA-COLA BRASIL (org.). A Coca-Cola Brasil tem controle em relação ao uso de agrotóxicos e/ou de agressão ao meio ambiente? Disponível em: https://www.cocacolabrasil.com.br/nos-respondemos/a-coca-cola-brasiltemcontrole-em-relacao-ao-uso-de-agrotoxicos. Acesso em: 16 nov. 2020e

COCA-COLA BRASIL (org.). Embalagens: como repensá-las sob a perspectiva da economia circular? Disponível em:

https://www.cocacolabrasil.com.br/historias/embalagens-como-repensa-las-soba-perspectiva-da-economia-circular. Acesso em: 13 nov. 2020c

COCA-COLA BRASIL (org.). Junte e Troque: Coca-Cola Brasil promove nova campanha para estimular uso de embalagens retornáveis. Disponível em: https://www.cocacolabrasil.com.br/imprensa/release/junte-troque-coca-colabrasil-promove-nova-campanha-para-estimular-uso-de-embalagens-retornaveis. Acesso em: 11 nov. $2020 \mathrm{~g}$ 
COCA-COLA BRASIL (org.). Linha do tempo: conheça a história da CocaCola Brasil. Disponível em: https://www.cocacolabrasil.com.br/sobre-a-cocacola-brasil/a-historia-da-coca-cola-brasil. Acesso em: 02 nov. 2020a

COCA-COLA BRASIL (org.). Relatório de Sustentabilidade Coca-Cola Brasil 2017. Disponível em:

https://www.cocacolabrasil.com.br/content/dam/journey/br/pt/private/pdfs/relatorio -de-sustentabilidade-coca-cola-brasil-2017.pdf. Acesso em: 12 nov. 2020b

COCA-COLA BRASIL (org.). Relatório de Sustentabilidade Coca-Cola Brasil 2018. Disponível

em:https://www.cocacolabrasil.com.br/content/dam/journey/br/pt/private/pdfs/relat orio-de-sustentabilidade-coca-cola-brasil-2018-baixa.pdf. Acesso em: 12 nov. 2020 e

COCA-COLA BRASIL (org.). Relatório de Sustentabilidade Coca-Cola Brasil 2019. Disponível em:

https://www.cocacolabrasil.com.br/content/dam/journey/br/pt/private/pdfs/relatorio -de-sustentabilidade-2019.pdf. Acesso em: 12 nov. 2020d

COSTA, Alessandra Mello da; CARVALHO, José Luis Felício. Legitimando papéis ou conciliando interesses? A reprodução discursiva da responsabilidade social empresarial. In: ENCONTRO NACIONAL DA ASSOCIAÇÃO NACIONAL DE PÓS-GRADUAÇÃO E PESQUISA EM ADMINISTRAÇÃO, 29., 2005, Brasília. Anais [...] . Brasília: Brasil, 2005. p. 0-16

DUPIM, Daiane Arruda de Almeida. Economia circular e biomimética: uma análise no contexto de sistemas regenerativos. 2019. $99 \mathrm{f}$. Dissertação (Mestrado) - Curso de Ciências da Engenharia Ambiental, Universidade de São Paulo, São Carlos, 2019.

ELLEN MACARTHUR FOUNDATION (org.). Economia Circular. Disponível em: https://www.ellenmacarthurfoundation.org/pt/economia-circular/conceito. Acesso em: 20 set. $2020 a$

ELLEN MACARTHUR FOUNDATION (org.). Economia Circular: uma solução para reconstruir melhor. Disponível em: 
https://www.ellenmacarthurfoundation.org/assets/downloads/PT_DIGITAL_EMF_ Joint-Statement_FT-sizingL.pdf. Acesso em: 20 set. 2020b

\section{ELLEN MACARTHUR FOUNDATION (org.) Nova Economia do Plástico.}

Disponível em: https://www.ellenmacarthurfoundation.org/pt/act/nova-economiado-pl\%C3\%A1stico. Acesso em: 24 out. 2020c

ÉPOCA NEGÓCIOS ONLINE (org.). Coca-Cola é a maior poluidora por lixo plástico do mundo, segundo pesquisa. Disponível em:

https://epocanegocios.globo.com/Empresa/noticia/2019/12/coca-cola-e-maiorpoluidora-por-lixo-plastico-do-mundo-segundo-pesquisa.html. Acesso em: 05 nov. 2020

GEJER, Léa; TENNENBAUM, Carla. Ciclo Técnico e Ciclo Biológico. 2017. Disponível em: https://www.ideiacircular.com/ciclo-tecnico-e-ciclo-biologico/. Acesso em: 25 out. 2020

GENG, Yong et al. Towards a national circular economy indicator system in China: An evaluation and critical analysis. Journal of Cleaner Production. Amsterdã, p. 216-224. mar. 2012

GIL, Antônio Carlos. Métodos e Técnicas de Pesquisa Social. 5. ed. São Paulo: Atlas, 1999. $248 \mathrm{p}$

GIOVANELLI, Anderson. Triple bottom line ou tripé da sustentabilidade. 2015. Disponível em: https://logisticareversa.org/2015/06/15/triple-bottom-lineou-tripe-da-sustentabilidade/. Acesso em: 07 out. 2020

GLOBAL REPORTING INITIATIVE (org.). Padrões da GRI - Traduções para o português. Disponível em: https://www.globalreporting.org/how-to-use-the-gristandards/gri-standards-portuguese-translations/. Acesso em: 10 Nov. 2020

JENKIN, S.; ZARI, M. P. Rethinking our built environments: Towards a sustainable future. Nova Zelândia: Ministério do Meio Ambiente da Nova Zelândia, 2009, 45p. 
tendências. 3. ed. São Paulo: Saraiva, 2015. 560 p.

LEITE, Paulo Roberto. Logística Reversa: Nova área da logística empresarial. Revista Tecnologística, São Paulo, 6 p., 2002

LEMOS, Ângela Denise da Cunha. A produção mais limpa como geradora de inovação e competitividade: o caso da fazenda Cerro do Tigre. 1998. $182 \mathrm{f}$. Dissertação (Mestrado) - Curso de Administração, Universidade Federal do Rio Grande do Sul, Porto Alegre, 1998

LIEDER, Michael; RASHID, Amir. Towards circular economy implementation: a comprehensive review in context of manufacturing industry. Journal of Cleaner Production. Amsterdã, p. 36-51. 2016. Disponível em:

https://doi.org/10.1016/j.jclepro.2015.12.042. Acesso em: 15 set. 2020

LYLE, John Tillman. Regenerative Design for Sustainable Development. Nova lorque: Wiley, 1996. $352 \mathrm{p}$

MCDONOUGH, William; BRAUNGART, Michael. Cradle to Cradle: Remaking the Way We Make Things. Nova lorque: North Point Press, 2002. $208 \mathrm{p}$

MESQUITA, João Lara. Coca-Cola e plástico no mar: poluição tem que parar. Disponível em: https://marsemfim.com.br/coca-cola-e-plastico-no-marisso-tem-queparar/\#: :text=A\%20organiza\%C3\%A7\%C3\%A30\%20acusa\%20a\%20Coca,que \%20mais\%20poluem\%20os\%20oceanos. Acesso em: 07 nov. 2020

MEU RESÍDUO (org.). A gestão de resíduos na indústria de bebidas.

Disponível em: https://meuresiduo.com/categoria-1/a-gestao-de-residuos-naindustria-de-bebidas/. Acesso em: 08 nov. 2020

MORAES, Carlos Alberto Mendes. Fluxograma da geração de opções de produção mais limpa. Disponível em:

https://www.researchgate.net/figure/Figura-1-Fluxograma-da-geracao-de-opcoesde-Producao-mais-Limpa-5_fig1_320119196. Acesso em: 16 out. 2020

MORETTI, Sérgio Luiz do Amaral; CAMPANARIO, Milton de Abreu. A produção 
intelectual brasileira em responsabilidade social empresarial - RSE sob a ótica da bibliometria. Revista de Administração Contemporânea, [S.L.], v. 13, p. 6886, jun. 2009. FapUNIFESP (SciELO). http://dx.doi.org/10.1590/s141565552009000500006

NASCIMENTO, Luis Felipe. Gestão Ambiental e Sustentabilidade.

Florianópolis: Universidade Federal de Santa Catarina - UFSC, 2012. 148 p.

NINNI, Karina. Consumo cresce seis vezes em 50 anos. Disponível em: https://sustentabilidade.estadao.com.br/noticias/geral,consumo-cresce-seisvezes-em-50-anos,573880. Acesso em: 29 jun. 2010

OLIVEIRA, Gilvan. Segurança Binária: nem sempre o risco está for de alcance. Disponível em: https://segurancabinaria.wordpress.com/. Acesso em: 15 out. 2020

ORR, David W. Earth in Mind: On Education, Environment, and the Human Prospect. Island Press. Washington, D.C., p. 577-577. dez. 1996

RABELO, Laudemira Silva; LIMA, Patrícia Verônica P. Sales. Indicadores de Sustentabilidade: a possibilidade da mensuração do desenvolvimento sustentável. Rede - Revista Eletrônica do Prodema, Fortaleza, v. 1, n. 1, p. 5576, dez. 2007

REED, B. Shifting from "sustainability" to regeneration. Building Research \& Information, Massachusetts, v. 35, n. 6, p. 674-680, 2007.

RLEC - Reverse Logistics Executive Council. Disponível em: http://reverselogistics.com/. Acesso em: 28 out 2020

SAUVÉ, Sébastien; BERNARD, Sophie; SLOAN, Pamela. Environmental sciences, sustainable development and circular economy: Alternative concepts for trans-disciplinary research. Elsevier. Montreal, p. 48-56. jan. 2016

SESI - Serviço Social da Indústria. Responsabilidade Social e Cidadania: conceitos e ferramentas. Brasília: Sesi - Departamento Nacional, 2008. 201 p. 
SIMPÓSIO DE ENGENHARIA DE PRODUÇÃO, 17., 2010,

Bauru. Sustentabilidade corporativa como suporte a estratégia de

negócios: Evidências práticas de aplicação. Bauru: Unesp, 2010. 13 p.

STAHEL, Walter R. The circular economy. Nature, Londres, v. 531, p. 435-438, mar. 2016. Disponível em: https://www.nature.com/news/the-circular-economy1.19594. Acesso em: 20 set. 2020

THE COCA-COLA COMPANY (org.). Crônicas da Coca-Cola: Nasce uma ideia refrescante. Disponível em:

https://www.cocacolabrasil.com.br/historias/cronicas-da-coca-cola-nasce-umaideia-refrescante. Acesso em: 02 nov. 2020b

THE COCA-COLA COMPANY (org.). Mundo Sem Resíduos: The Coca-Cola Company anuncia meta ambiciosa para embalagens sustentáveis.

Disponível em: https://www.cocacolabrasil.com.br/historias/um-mundo-semresiduos-the-coca-cola-company-anuncia-meta-ambiciosa-para-embalagenssustentaveis. Acesso em: 13 Nov. 2020c

THE COCA-COLA COMPANY (org.). What is World Without Waste? Disponível em: https://www.coca-colacompany.com/faqs/what-is-worldwithoutwaste\#: :text=We\%20aim\%20to\%20help\%20collect,program\%20we\%20launche d\%20in\%202018. Acesso em: 22 set. 2020a

VAVOLIZZA, Renata. Estudo Sobre a Aplicabilidade da Teoria Cradle C2C para a Empresa Têxtil Catarinense. 2016. 162 f. Dissertação (Mestrado) Curso de Design, Universidade Federal do Paraná, Curitiba, 2016

VERGARA, Sylvia Constant. Projetos e Relatórios de Pesquisa em Administração. São Paulo: Atlas, 1998. $97 p$

WBCSD - World Business Council for Sustainable Development. Reporting matters: striking a balance between disclosure and engagement. 2017.

Disponível em: https://docs.wbcsd.org/2017/10/WBCSD_Reporting_matters_2017_interactive.pd f. Acesso em: 18 out. 2020. 